\title{
Del funduq a la alhóndiga: un espacio entre el emirato nazarí y el reino de Granada (s. XV-XVI) ${ }^{1}$
}

\section{From Funduq to Alhondiga: a Space between the Nasrid Emirate and the Kingdom of Granada (15th-16th century)}

\author{
María del Carmen Jiménez Roldán \\ Universidad de Granada \\ https://orcid.org/0000-0001-5484-3669
}

El trabajo que presentamos tiene dos objetivos principales: primeramente, conocer las principales características estructurales y funcionales del funduq; en segundo lugar, observar la evolución tanto estructural como funcional que estos espacios sufrieron dentro y fuera del territorio islámico. Para ello utilizaremos la información arqueológica disponible que se complementará con algunos datos provenientes de la documentación escrita. Así conoceremos el funduq clásico, un edificio de planta cuadrada o rectangular, con patio central y uno o varios pisos, dedicados el inferior a cuadras y almacenes y los superiores a alojamiento de los viajeros/mercaderes. De este edificio encontraremos dos variaciones. Por una parte, el fondaco, un espacio arrendado o donado por las autoridades musulmanas a las comunidades cristianas de mercaderes que cumplía con todas las necesidades de estos últimos (religiosas, sociales y económicas). Y por otra, la alhóndiga, una institución con unas funciones específicas de almacenamiento y recogida de impuestos de determinadas mercancías.

Palabras clave: funduq; alhóndiga; comercio; ciudad; Granada.
This work has two main objectives: first, to know the main structural and functional characteristics of funduq; secondly, observe the structural and functional evolution that these spaces underwent inside and outside the Islamic territory. For this we will use the available archaeological information that will be complemented with some data from the written documentation. We will know the classic funduq, a square or rectangular building, with a central patio and one or several floors, dedicated to the lower blocks and warehouses and the superior ones to accommodation for travelers/merchants. From this building we will find two variations. On the one hand, the fondaco, a space leased or donated by the Muslim authorities to the Christian communities of merchants that met all needs (religious, social and economic). And on the other, alhóndiga, an institution with specific functions for storing and collecting taxes on certain merchandise.

Key words: funduq; alhóndiga; commerce; city; Granada.

${ }^{1}$ Este trabajo se inscribe en el marco de la investigación que estoy desarrollando en la elaboración de mi tesis doctoral en la Universidad de Granada.

Copyright: (C) 2019 CSIC. Este es un artículo de acceso abierto distribuido bajo los términos de la licencia de uso y distribución Creative Commons Reconocimiento 4.0 Internacional (CC BY 4.0). 


\section{Introducción}

Aunque no siempre fue así, el principal lugar de desarrollo de los espacios comerciales en el mundo islámico fueron sus ciudades. Estas se organizaban de tal manera que el poder económico y el religioso adquirían, incluso físicamente, la centralidad de manera que la mezquita aljama marcaba un núcleo entorno al cual se establecía generalmente el área comercial ${ }^{2}$, al menos una de ellas, la más destacada. Más allá de este núcleo, espacio público, comenzaba la zona privada de la ciudad con los diferentes barrios que conformaban la misma, y aunque en algunos casos se pudieran establecer según las tribus, siguiendo el modelo de los antiguo samșa $r$, sobre todo en los primeros tiempos, también es verdad que en otros casos se pudieron respetar otros parámetros como la profesión, la religión, etc ${ }^{3}$. Cada uno de estos barrios contaba con mezquita, baños y pequeños zocos. El desarrollo urbano muestra su evolución a través de una serie de elementos señalados en su momento para el caso andalusí por Navarro Palazón y Jiménez Castillo: la subdivisión y fragmentación del parcelario, ocupación de nuevas áreas situadas alrededor de la ciudad (creando arrabales) así como de antiguos cementerios con nuevas construcciones, la modificación del trazado y de las dimensiones de las vías públicas y el crecimiento de los edificios en altura ${ }^{4}$. Este proceso de crecimiento y densificación de la ciudad islámica también podemos observarlo en algunos espacios comerciales y artesanales, generalmente desplazados a la periferia conforme creció la necesidad de espacio habitable en el interior del recinto urbano ${ }^{5}$. Entre los primeros, el elemento que más nos sirve como índice de estos cambios son los zocos extra-muros, los cuales pueden servir de origen a un arrabal ${ }^{6}$. En otras ocasiones pueden ser los propios emires, califas o sultanes los que dentro de su política edilicia favorecieran y afianzaran tanto el desarrollo económico como urbano de la ciudad ${ }^{7}$.Precisamente uno de estos últimos espacios será objeto del estudio que aquí presentamos: el funduq.

\footnotetext{
${ }^{2}$ Chalmeta Gedrón, El zoco medieval, p. 334; Torres Balbás, Ciudades, p. 9; Navarro Palazón y Jiménez Castillo, Las ciudades, pp. 53-54.

${ }^{3}$ Torres Balbás, Ciudades, pp. 173-174.

${ }^{4}$ Navarro Palazón y Jiménez Castillo, “Algunas reflexiones”, pp. 284-291.

${ }^{5}$ Navarro Palazón y Jiménez Castillo, "Algunas reflexiones”, p. 287.

${ }^{6}$ Epalza, "Espacios y sus funciones en la ciudad árabe", p. 13.

${ }^{7}$ Fábregas García, "La vida económica", p. 96.
} 
Para ello, en el primer apartado realizaremos una descripción tanto del edificio en sí, enumerando sus principales características estructurales, así como de las actividades que en su interior tenían lugar utilizando la información arqueológica disponible que se complementará con algunos datos provenientes de la documentación escrita.

En segundo lugar, observaremos la evolución tanto estructural como funcional que estos espacios sufrieron dentro y fuera del territorio islámico. En esa línea, por una parte, nos detendremos brevemente en los fondacos, edificios destinados a las comunidades cristianas de mercaderes que comerciaban en las diferentes regiones islámicas. Los abordaremos de manera diferenciada respecto a las alhóndigas, ubicadas en territorio cristiano, cuya principal modificación con el paso del tiempo reside en el cambio de actividades que se desempeñaban en su interior. Para ilustrar este caso de las alhóndigas nos remitiremos al ejemplo del reino de Granada, centrando nuestra atención en el caso de la capital, Granada, donde a través de la documentación conservada observamos las transformaciones que experimentaron estos inmuebles en los primeros años tras la conquista (primer tercio del s. XVI).

En la lengua árabe encontramos varias denominaciones para aludir a una misma idea de espacio vinculado al tránsito, al comercio. Resulta incluso mejor definido al espacio físico que acoge esta estructura que el nombre que este recibiera. En nuestro caso, hablamos generalmente de un edificio de planta cuadrada o rectangular, con patio central y uno o varios pisos, dedicados el inferior a cuadras y almacenes y los superiores a alojamiento de los viajeros. Esta estructura pudo instalarse en diferentes espacios, o al menos se reconoce con nombres diversos: ribāt, wakāla, caravasar, jāny funduq ${ }^{8}$.

Aunque la definición tradicional del ribāt, alude a conventos fortificados situados en las zonas costeras y fronterizas, habitados por musulmanes devotos que realizaban expediciones militares y prácticas ascéticas ${ }^{9}$, en los últimos años algunas investigaciones apuntan a una posible vinculación de estos espacios con el comercio, al menos

${ }^{8}$ Debemos aclarar que los términos wakāla, caravasar, jān, no se emplearon en la Península Ibérica. Su uso es más común en Egipto (Sennoune, "Fondouks, khans et wakalas à Alexandrie") y el Oriente islámico.

${ }^{9}$ Torres Balbás, "Rábitas hispanomusulmanas", p. 476. 
en la zona costera del Magreb occidenta ${ }^{10} \mathrm{y}$ en el levante peninsu$\operatorname{lar}^{11}$.

La wakāla, surgió como un espacio ocasionalmente dedicado al alojamiento, aunque sus funciones principales eran almacenamiento y el cobro de impuestos ${ }^{12}$, lo que permitió a las autoridades el control del comercio de determinados productos, como frutas, azúcar, seda, etc ${ }^{13}$.

Los tres últimos términos sí aluden de manera más directa al comercio: caravasares, jān y fanādiq. La diferencia entre estas tres denominaciones parece estar más vinculada a su ubicación que al desarrollo o especialización en algunas de las funciones generales ya mencionadas (comercio, alojamiento, almacén). Caravasar y jān, ambas palabras de origen persa, tienen en común el hecho de ser espacios ubicados en las rutas de caravanas. Los caravasares, surgieron durante el periodo sasánida, aunque fue en el islam cuando se concibieron como espacios para el descanso y alojamiento de viajeros, y de sus mercancías, en las rutas caravaneras que discurren por Asia Central. Por otro lado, el término jān es el más utilizado como sinónimo de funduq, apareciendo indistintamente al menos hasta el siglo XII, cuando el primero se reservaría ya para el área oriental del Mediterráneo, mientras que el segundo sería desde entonces utilizado preferentemente en el occidente islámico ${ }^{14}$. Sobre este nos centraremos a continuación.

\section{El funduq en al-Ándalus}

Nuestro conocimiento acerca del funduq ha sido bastante escaso durante largo tiempo. A excepción del tradicional trabajo de Torres Balbás, centrado en el único funduq que ha sobrevivido hasta nuestros días

${ }^{10}$ Cressier, "De un ribat a otro", pp. 203-221.

${ }^{11}$ Azuar Ruiz, "El ribat en al-Andalus", pp. 23-38.

${ }^{12}$ Constable, Housing the Stranger, p. 260.

${ }^{13}$ Constable, Housing the Stranger, p. 262.

14 "While the term khan gained ground in the Eastern Mediterranean, funduqs reamined much more common in the Islamic west. This distinction in regional usage is evident in the observations of Maghribi travelers writing regional usage is evident in the observations of Maghribi travelers writing about their experiences in Egypt and Syria. Their descriptions often use the word funduq for buildins called khan by natives of Mamluk realms" Constable, Housing the Stranger, p. 251. 
en la península ibérica, el funduq al-Ŷadīda de Granada ${ }^{15}$, poco más se tenía. El Corral del Carbón o funduq al-Ŷadìda, fue edificado en el s. XIV. Se trata de un inmueble casi cuadrado $(28,05 \times 29,60 \mathrm{~m})$ al que se accede a través de una portada monumental, inspirada en el iwan oriental. Estructurado en torno a un patio $(16,80 \times 15,60 \mathrm{~m})$ con una pila cuadrada central, al que rodean cuatro crujías (Figura 3). Cada una de ellas cuenta con tres alturas y está dividida en pequeñas habitaciones. El acceso a los pisos superiores se realizaba a través de las dos escaleras situadas en el centro de dos de los laterales ${ }^{16}$.

Por otro lado, en los últimos años, la publicación de los resultados de varias excavaciones arqueológicas, así como una monografía centrada en estos espacios ${ }^{17}$, ha contribuido a un conocimiento más exhaustivo $^{18}$. Los principales ejemplos que podemos ofrecer por el momento provienen de las ciudades de Córdoba (7) ${ }^{19}$, Almería (4) ${ }^{20}$ (Figura 1) y Murcia (3) $)^{21}$, complementadas con los edificios hallados en Granada ${ }^{22}$ (Figura 7), Valenciaa ${ }^{23}$, Loja (Granada) ${ }^{24}$, Rincón de la Victoria (Málaga) ${ }^{25}$, Málaga ${ }^{26}$ y Denia ${ }^{27}$.

${ }^{15}$ Torres Balbás, "Las alhóndigas hispanomusulmanas", pp. 447-484.

${ }^{16}$ Torres Balbás, "Las alhóndigas hispanomusulmanas", pp. 463-468.

${ }^{17}$ Constable, Housing the Stranger.

${ }^{18}$ A todo esto, debemos añadir la tesis que está llevando a cabo Alicia Hernández Robles sobre estos espacios en la Universidad de Murcia.

${ }^{19}$ Casal, "Informe-Memoria de la I.A.U.", p. 352; Vázquez Navajas, "El agua en la Córdoba andalusí", p. 36; Clapés Salmoral, "La actividad comercial de Córdoba”, pp. 225254. De las tres edificaciones identificadas en la zona II de la Ronda Oeste solo contamos con la mención que realiza Vázquez Navajas, Arqueología hidráulica, p. 471.

${ }^{20}$ García López, Cara Barrionuevo, Flores Escobosa y Morales Sánchez, "La organización de espacios", pp. 13-29; Cara Barrionuevo, García López y Morales Sánchez, “Arqueología urbana e historia de la ciudad", pp. 167-192; Cara Barrionuevo y Morales Sánchez, "Instalaciones industriales", pp. 36-46.

${ }^{21}$ Ruiz Parra, "Excavaciones arqueológicas en el solar", pp. 416-426; Jiménez Castillo y Navarro Palazón, “Casas y tiendas”, pp. 490-532; Jiménez Castillo y Navarro Palazón, "Murcia omeya", pp. 132-151.

${ }^{22}$ Arroyo Pérez et al., "Excavación arqueológica de urgencia en la alhóndiga Zayda", pp. 279-283. En el momento de preparación de este trabajo, sabemos que se están desarrollando trabajos arqueológicos en el solar antiguamente ocupado por la alhóndiga de los genoveses en Granada. Esperamos en breve poder conocer los resultados de estos trabajos dirigidos por el arqueólogo Ángel Rodríguez Aguilera a quien agradecemos la información.

${ }^{23}$ Martí Oltra y Burriel Alberich, "Comerciar en tierra extraña", pp. 41-60.

${ }^{24}$ Buendía Moreno y Álvarez, "Un posible Funduq nazari'”, pp. 1344-1348.

${ }^{25}$ Florido Esteban, "Intervención arqueológica", pp. 3305-3309.

26 Íñiguez Sánchez, "De la Málaga emiral”, pp. 3398-3425.

${ }^{27}$ Gisbert, "Daniya, reflejo del Mediterráneo", p. 213. 


\subsection{Características arquitectónicas que definen la estructura del funduq}

Los fanādiq son espacios de planta cuadrada o rectangular, con una superficie que varía entre los $230 \mathrm{~m}^{2}$ del edificio excavado en la esquina de la calle Corretgeria con la plaza de la Reina (Valencia) en el año $2000^{28}$, y los $830 \mathrm{~m}^{2}$ del funduq al-ŶYadīda de la ciudad granadina ${ }^{29}$.

Mayoritariamente la entrada a estos inmuebles se realizaba de forma directa desde la calle principal, excepcionalmente a través de una gran portada como la conservada en el funduq al-Ŷadìda de Granada ${ }^{30}$ o la localizada en el edificio excavado en 2003 en el solar situado entre las calles Chafarinas, Pedro Jover y San Juan (Almería) ${ }^{31}$. Sin embargo, conocemos algunos ejemplos que nos muestran que este acceso también podía realizarse de manera indirecta por un lateral o a través de un adarve. Así ocurre en Almería, en la calle Tiendas ${ }^{32}$, o en el yacimiento de Llano de la Torralba (Rincón de la Victoria, Málaga), excavado en 2006, donde la calle que daba acceso al establecimiento del s. XI-XII se cierra en un momento determinado, quedando como adarve o como unas posibles caballerizas ${ }^{33}$. De todos, el mejor conocido es el caso del funduq (s. X) excavado en la Manzana 14 del Plan Parcial O7 de Córdoba (Figura 2). Un edificio del siglo X con una estructura de planta rectangular (de unos $279,62 \mathrm{~m}^{2}$ ), y cuya entrada se realizaría por una calle en recodo, situada en la esquina suroeste del complejo, con una serie de estancias a los lados, una en el occidental y tres en el orienta $^{34}$.Otro ejemplo, excavado entre los años 2001-2003, en el arrabal de Šaqunda (s. VIII-IX), correspondiente a la actual área del Parque de Miraflores y Centro de Congresos de Córdoba, donde se identificó un inmueble flanqueado por un gran espacio abierto, cuyo acceso se localiza en el lateral occidental ${ }^{35}$.

${ }^{28}$ Martí Oltra y Burriel Alberich, "Comerciar en tierra extraña", p. 56.

${ }^{29}$ Torres Balbás, "Las alhóndigas hispanomusulmanas", p. 463.

${ }^{30}$ Torres Balbás, "Las alhóndigas hispanomusulmanas", p. 464.

${ }^{31}$ Cara Barrionuevo y Morales Sánchez, "Instalaciones industriales", p. 42.

${ }^{32}$ Cara Barrionuevo, García López y Morales Sánchez, "Arqueología urbana e historia de la ciudad", p. 172.

${ }^{33}$ Florido Esteban, "Intervención arqueológica”, p. 3307.

${ }^{34}$ Clapés Salmoral, "La actividad comercial de Córdoba", pp. 244-245.

${ }^{35}$ Casal, "Informe-Memoria de la I.A.U.", p. 352. 
Estos accesos daban paso al espacio central en torno al cual se organizaban este tipo de construcciones, el patio. En el centro se identifica en casi todos los ejemplos un pozo, fuente o alberca, a excepción del edificio de la calle Corretgeria (Valencia) donde el pozo se localizó en uno de los laterales ${ }^{36}$ (Figura 6). Alrededor del patio transcurre un andén que permite la entrada a las diferentes estancias, en ocasiones porticado total o parcialmente. La presencia de estos pórticos se relaciona con la posible existencia de una segunda planta, pero esta afirmación debe ser matizada, al no haberse encontrado en ninguno de los ejemplos conocidos las escaleras de acceso. Además, no en todos los casos se han documentado estos pórticos, señalando por tanto edificios con una sola planta, que también encontramos en referencias textuales:

"Un fondouk est la propriété indivise de deux hommes. Il est situé dans un espace découvert et limité de tous les côtés par des jardins et une route; il est dépourvu d'étage, renferme des chambres et des appentis pour les montures" ${ }^{\text {"37. }}$.

A cada lado del patio se abre una crujía con una anchura que oscila entre 2,10 y $3,40 \mathrm{~m}$, dividida a su vez en una serie de estancias de similar tamaño entre ellas, cuyo uso es muy diverso: desde servir como habitaciones para viajeros/comerciantes (así como para el encargado del funduq), almacén de las mercancías, establo, tienda, taller y/o letrinas. Estas últimas son fácilmente identificables por la estructura hidráulica necesaria para su desagüe, aunque no presentan una ubicación determinada. Las encontramos en el adarve de acceso de uno de los edificios excavados en Córdoba ${ }^{38}$; en el centro de una crujía con un pequeño zaguán antecediéndola, en el inmueble de los siglos X-XI excavado entre los meses de enero y marzo de 2001 en un solar de la plaza Santa Eulalia (Murcia) ${ }^{39}$; en una de las esquinas como ocurre en el caso excavado en la calle Marqués de Campo en Denia ${ }^{40}$; e incluso en el establecimiento de Valencia (s. XII) se ha propuesto la existencia de las letrinas en la segunda planta, al encontrar que en una de las canaliza-

${ }^{36}$ Martí Oltra y Burriel Alberich, "Comerciar en tierra extraña”, p. 56.

${ }^{37}$ Lagardère, Histoire et société, p. $368, \mathrm{n}^{\circ} 342$. Resume una consulta hecha al granadino Abū Sa'īid b. Lubb (m. 782/1381).

${ }^{38}$ Clapés Salmoral, "La actividad comercial de Córdoba", p. 245.

${ }^{39}$ Jiménez Castillo y Navarro Palazón, "Murcia omeya", p. 148.

${ }^{40}$ Gisbert, "La ciudad y la cocina". 
ciones secundarias desagua una bajante situada en el interior de una de las estancias, encastrada en el muro:

El conducto principal arrancaba de la esquina SW del patio, donde recogía las aguas de una bajante encastrada en el muro, y recorría el patio pegado al muro meridional para girar luego hacia el sur y salir a la calle tras atravesar la estancia delantera del edificio. A esta canalización principal vertían otras secundarias, una que recogía el agua de la panda norte, otra más estrecha que desaguaba la pila antes comentada, y una tercera que recorría la habitación delantera y se entregaba a la anterior en el centro de la estancia. Esta última servía para desaguar otra bajante, pero en este caso situada, no en el patio, sino en el interior de una estancia encastrada en uno de los muros. Esta circunstancia resulta singular, pues lo habitual es que las cubiertas desagüen en el patio, ya sea mediante canalones y gárgolas o a través de bajantes de cerámica. Por ello, sin descartar que se trate de un aliviadero del tejado, cabe la posibilidad de que estemos ante la canalización de una pila o una letrina situada en el piso alto, una circunstancia insólita en la arquitectura doméstica de este momento ${ }^{41}$.

\subsection{Funciones de los fanādiq}

Las funciones principales que cumplían estos establecimientos eran las de hospedaje y almacenamiento. En lo que se refiere al alojamiento, sabemos que una de las estancias estaba reservada a la persona encargada de la vigilancia y mantenimiento del edificio. En el Corral del Carbón, Torres Balbás la situó encima de la puerta de acceso ${ }^{42}$, mientras que Josep Gisbert en el edificio de la calle Marqués del Campo (Denia) la ubicó en uno de los laterales ${ }^{43}$. Por otra parte, Iñiguez Sánchez en un solar entre las calles Sebastián Souviron, Olozaga y Marqués (Málaga) identifica una estructura delos siglos X-XI formada por dos naves rectangulares paralelas, que ocupan un área de unos $223,60 \mathrm{~m}^{2}$, sin espacio abierto central, las cuales relaciona con un posible uso exclusivo destinado al alojamiento ${ }^{44}$. Las áreas de almacenamiento de mercancías han sido localizadas en la excavación realizada en Almería, en el inmueble hallado en la calle Santísima Trinidad entre septiembre y octubre de 2001. Se trata de un solar que en una primera fase estuvo ocupado por una tenería y que, tras un periodo de abandono, el edificio

${ }^{41}$ Martí Oltra y Burriel Alberich, "Comerciar en tierra extraña", p. 57.

${ }^{42}$ Torres Balbás, "Las alhóndigas hispanomusulmanas", p. 465.

${ }^{43}$ Gisbert, "La ciudad y la cocina".

${ }^{44}$ Íñiguez Sánchez, "De la Málaga emiral”, p. 3414. 
cambió su funcionalidad (segunda mitad del siglo XII). Se identificó un muro orientado N-S del cual partían otros transversales, dirección $\mathrm{E}-\mathrm{W}$, configurando una serie de estancias rectangulares en la que se hallaron un gran número de vasijas de almacenaje ${ }^{45}$.

Existen otros ejemplos similares, en la misma Almería y en Córdoba, si bien han sido relacionados con la actividad comercial, no así con un funduq. En la capital almeriense, en el solar de la calle Real $\mathrm{n}^{\circ}$ 84, en una actividad arqueológica desarrollada entre los meses de septiembre y noviembre de 2008, se identificó un espacio de tendencia rectangular $(10 \times 8 \mathrm{~m})$ limitado al noroeste por una calle. En el interior de esta estructura (finales s. XI - primer tercio del XII) se identificó un banco corrido donde se situaban una sucesión de grandes tinajas (diámetro de la boca $1,20 \mathrm{~m}$ y una altura de $1 \mathrm{~m}$ ) vinculadas con el almacenamiento de productos ${ }^{46}$. En el inmueble (ss. XI-XII) excavado en Córdoba en la Avenida de América ${ }^{\circ} 5$ durante los meses de julio y octubre de 2007, se hallaron en algunos de los sectores una serie de tinajas que funcionarían como silos ${ }^{47}$.

En el occidente islámico los fanādiq no sólo cumplían estas funciones, sino que también se identifican otras relacionadas con la venta o con la elaboración de productos. En dos excavaciones en la ciudad de Murcia se identificaron varias tiendas o espacios donde estas podrían ubicarse. La primera (Figura 4), en un solar de $300 \mathrm{~m}^{2}$ en la esquina que forma la calle Pascual con la calle Conde Valle de San Juan, excavado entre enero de 1989 y junio de 1990, dio como resultado el hallazgo de cuatro crujías acodadas paralelas, que conformaban la esquina suroeste de un edificio de grandes dimensiones y complejidad (siglo XII-XIII) ${ }^{48}$. La crujía más externa se hallaba dividida en ocho espacios rectangulares, en dos de los cuales se identificaron vanos que abrían a la calle, por lo que cabe la posibilidad de que se trataran de tiendas. La segunda crujía se encontró compartimentada en tres partes desiguales, mientras que la tercera aparece sin divisiones de ningún tipo. Por último, la crujía interior se encontraba subdividida en varias dependencias de tamaño irregular ${ }^{49}$.

${ }^{45}$ Cara Barrionuevo y Morales Sánchez, "Instalaciones industriales”, p. 39.

${ }^{46}$ Embí Najar y Mellado Sáez, "Intervención arqueológica", p. 90.

${ }^{47}$ Molina Expósito, “Actividad arqueológica preventiva”, pp. 1627-1628.

${ }^{48}$ Ruiz Parra, "Excavaciones arqueológicas en el solar", pp. 416-426.

${ }^{49}$ Ruiz Parra, "Excavaciones arqueológicas en el solar”, p. 420. 
La segunda excavación se desarrolló entre noviembre de 1993 y enero de 1995 en el solar limitado por la calle Frenería, la calle San Patricio y la plaza Belluga al N, S y E, respectivamente, mientras al W limitaba con otra propiedad ${ }^{50}$ (Figura 5). En esta ocasión nos interesa especialmente el sector oriental del solar, donde se identificó un establecimiento también de grandes proporciones ${ }^{51}$. Cuenta con un patio central $(7 \times 8,5$ $\mathrm{m}$ ) en torno al cual se disponen al menos tres crujías, ya que la occidental muy probablemente no existía, al encontrarse al otro lado los restos de una vivienda. Al norte de la crujía septentrional se plantea la posibilidad de que se hallase ocupado por tiendas, continuando con las existentes en el sector occidental del solar excavado ${ }^{52}$.

En lo que se refiere a su uso como taller, se producía cuando un determinado grupo de artesanos alquilaban un funduq, transformándolo así en un lugar de trabajo colectivo ${ }^{53}$. Existen varios testimonios textuales que reflejan esta realidad, tanto en al-Ándalus ${ }^{54}$ como en el Magreb $^{55}$. Resulta particularmente interesante cómo se reflejan en los habices granadinos estos espacios. Como se recoge en el cuadro 01 del anexo se citan alhóndigas aludiendo a la actividad que se desarrollaba en su interior, caso de la "alhóndiga de cereros", "donde ponen los lienzos los curanderos" o "donde espadan el lino". Otros ejemplos (cuadro 02) reflejan una serie de espacios similares a los anteriores, pero que se registran con el término "casa" en lugar de "alhóndiga": dos casas de cereros o cerveros ${ }^{56}$, casa donde bruñen los lienzos, y dos casas de espadadores, una de las cuales se encontraba caída. Por otro lado, en la intervención arqueológica realizada en el Teatro Cine Imperial de Loja (Granada), en el año 2006, se halló un inmueble nazarí organizado en torno a un patio con un pozo más o menos centralizado.

${ }^{50}$ Jiménez Castillo y Navarro Palazón, “Casas y tiendas”, pp. 490-532.

${ }^{51}$ El sector occidental por su parte dio como resultado la identificación de cuatro casas, así como de cuatro tiendas.

52 Jiménez Castillo y Navarro Palazón, "Casas y tiendas", p. 523.

${ }^{53}$ Chalmeta Gedrón, El zoco medieval, pp. 302-304.

54 "E conprólos Alí Hestalil e metiól en vna alfóndiga con otros LX christianos que tenían en su prisión. E façían labrar a este Rodrigo cada día dentro en la alfóndiga esparto". González Jiménez y Molina Molina, Los Milagros romanzados, p. 82.

55 "On y trouve notamment le potier et le tourneur. Quelques récits nous permettent de constater que plusieurs artisanats sont exercés dans des funduq (caravansérails)" Allaoua, "L'apport des sources", p. 211.

${ }^{56}$ Ambos términos, malas lecturas de çerreros, remiten a la misma actividad. 
Dispone de una serie de habitaciones en los lados N, S y E, en algunas de las cuales se documentaron hogare ${ }^{57}$ que podrían estar en relación con el desarrollo de alguna actividad artesanal ${ }^{58}$.

Un último aspecto a tratar es el referente a la propiedad de estos inmuebles. Esta era muy variada, ya que conocemos, por ejemplo, edificios pertenecientes al patrimonio real, como el caso del funduq al-Ŷadìda, que posiblemente fuera construido en la época de Yūsuf I ${ }^{59}$ y que se integraba dentro del conocido como "patrimonio de las reinas moras" 60 ; otras de estas construcciones formaban parte de los bienes habices ${ }^{61}$, como ha quedado reflejado en el caso de Granada (cuadro 01) y, por último, otras eran de propiedad privada o individual, como observamos en los dos documentos transcritos en el anexo 1 de este trabajo. En el primer documento 1.A, formado por tres escrituras, vemos la compra, el pago y la venta de una alhóndiga (utilizado como castellanización del término funduq) en el arrabal de Bibarrambla. Mientras la compra y el pago se realiza entre Mahamad, hijo de Hamete el Fordoz, y el mercader Abulcaçim, hijo de Mahamad Abenhador, la venta sucede entre el mencionado Mahamad, hijo de Hamete el Fordoz, y Gonzalo Martínez, escribano del alcalde juez de Granada, y su mujer. Por otra parte, en el documento 1.B, las dos alhóndigas que se mencionan pasaron a manos del obispo de Guadix. La primera, en la cual

\footnotetext{
${ }^{57}$ Buendía Moreno y Álvarez, "Un posible Funduq nazarí”.

${ }^{58}$ Buendía Moreno y Álvarez, "Un posible Funduq nazarí”, p. 1345.

${ }^{59}$ Gómez Moreno, Guía de Granada, p. 197.

${ }^{60}$ Torres Balbás, "Las alhóndigas hispanomusulmanas", pp. 453-454; Gaspar Remiro, "Partida de Boabdil", pp. 87-88.

61 "El principal modo de explotación de los bienes $a h b \bar{a} s$ era el alquiler o arrendamiento, pues se trataba del sistema más utilizado a fin de rentabilizar las propiedades así establecidas" (Carballeira Debasa, Legados píos, p. 297). "La consulta donde se aludía al arrendamiento de dos alhóndigas constituidas en hubs a favor de una frontera musulmana. Como ya he indicado en su momento, debido a los avatares anteriores a la fundación pía fue preciso distribuir las rentas del arrendamiento entre varias partes que tenían derecho al solar, para compensarles económicamente a causa del terreno que no podían explotar debido a la existencia del hubs. De este modo, con el arrendamiento de cada año una parte del mismo se destinaba a la frontera, siguiendo los términos del acta fundacional del hubs; otra se asignaba a los herederos del padre del fundador y otra revertía en el Tesoro Público" (Carballeira Debasa, Legados píos, pp. 298-299). Estos alquileres tenían una duración máxima de 4 años y en el caso de las alhóndigas podía reducirse la cantidad del arrendamiento a cusa de un desorden social, inseguridad en los caminos, o cualquier otra causa que hiciera disminuir el número de huéspedes (García Sanjuán, Hasta que Dios, pp. 134-138; Carballeira Debasa, Legados pios, p. 307).
} 
se centra el documento, la compró Alonso Lobo, canónigo de la iglesia mayor de Guadix, en la puerta de "Biba Almazán"62 a Albucaçim Abendafa, mientras que la segunda lindaba con la anterior y perteneció a Mahoma Albarrani.

\section{El fondaco. Evolución internacional del funduq}

El funduq no resultaba una estructura estática, sino que fue adaptada por la propia comunidad islámica e incluso por comunidades cristianas para sus propias necesidades. Así, por ejemplo, a partir del siglo XII con la llegada de mercaderes procedentes de algunas ciudades del sur de Europa (venecianos, pisanos, genoveses, entre las principales, pero tampoco debemos olvidar otras como catalanes y valencianos) a los mercados de los países islámicos, las autoridades de estos últimos tuvieron que encontrar la solución a una serie de necesidades que planteaban estas comunidades cristianas. A ambas partes les preocupaba que estos mercaderes estuvieran bien alojados, sus mercancías almacenadas adecuadamente, pudieran comerciar con ellas con seguridad y pagasen sus respectivos impuestos ${ }^{63}$.

La solución se plasmó en tratados. Cada comunidad buscaba el mejor acuerdo con las mejores ventajas, especialmente económicas. Un aspecto interesante de estos pactos era el hecho de otorgarle un espacio propio a estos visitantes. Esto se concretó en un funduq o como lo denomina Constable, fondaco, utilizando el término italiano para diferenciarlo de la expresión árabe. Porque, aunque ambos vocablos nacieron para identificar una misma institución ${ }^{64}$, pronto el fondaco se desarrolló como una institución propia, con características identificativas que lo diferenciaban del funduq.

La presencia de un fondaco en una ciudad islámica determinada estaba vinculada y justificada por la existencia de un número suficiente

\footnotetext{
${ }^{62}$ Castellanización del árabe Bāb al-Mașda: puerta del corro. Seco de Lucena Paredes "Las puertas de la cerca", p. 445. "Es una puerta de la ciudad y no del arrabal, comunicando de forma directa con una de las vías interiores de importancia que conectaba con la calle Elvira, encontrándose abierta en el trazado de la muralla urbana"; Rodríguez Aguilera, $L a$ puerta de Bibarrambla, p. 316.

${ }^{63}$ Constable, Housing the Stranger, p. 109.

${ }^{64}$ Constable, Housing the Stranger, p. 110.
} 
de extranjeros ${ }^{65}$. Eran edificios propiedad del soberano ${ }^{66}$, que donaba o alquilaba a la comunidad de comerciantes correspondiente ${ }^{67}$. El arrendamiento (total o parcial ${ }^{68}$ ) de este espacio, así como los gastos internos del mismo eran pagados por el cónsul ${ }^{69}$. En ocasiones estos inmuebles podían pasar de una comunidad a otra, como ocurrió con el fondaco pisano en Túnez, que pasó a manos genovesas debido al auge de los segundos en detrimento de los primeros ${ }^{70}$. Un dato interesante en este sentido lo encontramos en Ifriqiya, donde el rey de Aragón tiene la titularidad del fondaco ${ }^{71}$ mallorquín. Es un aspecto que marca la rivalidad comercial existente entre mallorquines y catalanes, derivada de la propia división de la Corona ${ }^{72}$. Aunque se ha propuesto la existencia de fondaci de cristianos, donde se agruparían comerciantes de distinta procedencia, lo cierto es que no se ha encontrado evidencia alguna. Con todo en Túnez la zona donde se ubicaban los establecimientos de genoveses y venecianos era conocida como "fondaco dei cristiani" 73 cercana a la Puerta del Mar. En Málaga observamos cómo en las negociaciones con los venecianos, se menciona que el edificio de estos estaría ubicado junto a los fondaci de los demás cristianos ${ }^{74}$.

Si bien estos fondaci tienen su origen en los fanādiq árabes, las necesidades de una comunidad cristiana de cierto peso pudieron influir en la modificación estructural y funcional de estos edificios. Así por ejemplo, el originario edificio de planta cuadrada con patio central que acabamos de describir como arquetipo, se convertiría en una estructura más compleja, con casas para comerciantes, almacenes, aduana, tiendas, espacios artesanales, pozo, horno, iglesia e incluso cementerio ${ }^{75}$.

${ }^{65}$ Valérian, "Le Fondouk, instrument", p. 680.

${ }^{66}$ Valérian, "Le Fondouk, instrument", p. 689.

${ }^{67}$ Petti Balbi, Negoziare fuori patria, p. 8.

${ }^{68}$ Como queda reflejado en las negociaciones del tratado entre el reino nazarí y los comerciantes venecianos el mantenimiento del consulado se realizaría de manera conjunta. Fábregas García, “Acercamientos y acuerdos”, p. 650.

${ }^{69}$ Petti Balbi, Negoziare fuori patria, p. 224.

${ }^{70}$ Doumerc, Venise et l'émirat, p. 155.

${ }^{71}$ Denominado con el término catalán, alfòndec.

${ }^{72}$ López Pérez, "Política y comercio", p. 425 p. 250.

${ }^{73}$ Brunschvig, La berbérie orientale, vol. I, p. 347; Petti Balbi, Negoziare fuori patria,

${ }^{74}$ Fábregas García, “Acercamientos y acuerdos”, p. 653. p. 208 .

${ }^{75}$ Valérian, "Le Fondouk, instrument", p. 683 ; Petti Balbi, Negoziare fuori patria, 
De esta forma, lo que en un principio se identificaba como un edificio, pudo llegar a conformar un barrio que reuniría todos los elementos necesarios para la vida de una comunidad cristiana ${ }^{76}$.

Estos se encontraban rodeados por una muralla que separaba a la comunidad cristiana del resto de la ciudad ${ }^{77}$. Y precisamente aquí reside la principal diferencia y característica del fondaco. Este espacio crea un estado de extraterritorialidad donde no se reconoce el poder musulmán y se aplica la jurisdicción del país originario correspondiente representado en el cónsul ${ }^{78}$. Por tanto los muros que los rodean son una frontera real, que permite un rápido y seguro intercambio mercantil pero que impide el establecimiento de relaciones más allá de este ámbito $^{79}$.

\section{Las alhóndigas. El ejemplo de la ciudad de Granada}

En la Península Ibérica, por otro lado, conforme avanzaba la conquista cristiana sobre territorio islámico, fueron también multiplicándose las alhóndigas en territorio cristiano. Estas, al contrario que los fondaci, se consideran resultado de la evolución del funduq en territorio cristiano. Aunque en ciertas ocasiones se ha pensado que el término alhóndiga tan sólo era una castellanización de la palabra árabe, siendo utilizadas ambas para referirse a la misma institución y, por tanto, como sinónimos. Sin embargo, esta idea debe ser matizada.

Para ello nos centraremos en el caso del emirato nazarí de Granada con especial atención a la capital del mismo, y observaremos las transformaciones que sufrieron estos inmuebles en el primer tercio del siglo XVI (Figura 8).

\footnotetext{
${ }^{76}$ Petti Balbi, Negoziare fuori patria, p. 7.

77 Tuccio di Gennaio en su correspondencia nos relata la sensación de encierro que producían los muros de estas edificaciones. Fábregas García, "Estrategias de los mercaderes", pp. 259-304.

${ }^{78}$ Valérian, "Le Fondouk, instrument”, pp. 692-694; Petti Balbi, Negoziare fuori patria, pp. 88-89.

${ }^{79}$ Petti Balbi, Negoziare fuori patria, p. 224. 


\subsection{Alhóndiga como traducción del árabe funduq}

La utilización del vocablo castellano como sinónimo del árabe debe circunscribirse a los momentos inmediatamente posteriores a la conquista de una determinada ciudad. Se refleja especialmente en la documentación conservada relativa a la capital granadina, tanto de época islámica como cristiana. En lo que se refiere a la documentación árabe encontramos dos grandes grupos de escrituras: las conservadas en árabe ${ }^{80} \mathrm{y}$ las romanceadas, generalmente copias o traslados de los originales árabes. De las primeras destacamos un ejemplo muy concreto, del cual Seco de Lucena publicó un resumen de la compra de una almacería la cual lindaba con una alhóndiga de Abu Sitta:

Abu Ali Husayn b. Ali al-Malaqi compra a Aisa bt. Muhammad al-Ubadi una almacería situada en el al-Hattabin al-Mahruqa por precio de 20 dinares de oro al cambio acostumbrado. Entre las lindes figura la alhóndiga (fondaq) de Abu Sitta ${ }^{81}$.

Por otro lado, se encuentran las escrituras árabes traducidas o romanceadas, de las cuales la mayoría son escrituras de propiedad de particulares, delimitación de lindes entre concejos municipales, cesión de privilegios por parte de los reyes nazaríes a ciertos municipios, o bien testamentos mencionando la propiedad de determinados inmuebles. Se encuentran insertas o forman parte de las pruebas que se aportan en pleitos entre particulares por la propiedad de bienes inmuebles, relativos al reparto de aguas o jurisdiccionales entre los nuevos concejos formados tras la conquista ${ }^{82}$. En este caso, las escrituras editadas en el anexo 1.A son un conjunto de tres escrituras sobre la compra, pago y venta de una alhóndiga en el arrabal de Bibarrambla. Forman parte del pleito localizado en el Archivo de la Real Chancillería de Granada (A.R.Ch.Gr., caja 5417, pieza 5) entre Gonzalo Martínez, escribano público y vecino de Granada, y Leonor Martínez, hija y heredera del mencionado Gonzalo Martínez, contra Gerónimo de Madrid, abad de Santa Fe, por una deuda debido al impago de un censo. Así estas escrituras junto con otras dos referentes a una casa en la villa de Santa Fe y una casa-tarbea con una

${ }^{80}$ Un análisis de este tipo de documentación los encontramos en los siguientes trabajos: Zomeño Rodríguez, "Del escritorio al tribunal”, pp. 75-98; Zomeño Rodríguez, "Los notarios musulmanes", pp. 195-209.

${ }^{81}$ Seco de Lucena Paredes, "Escrituras árabes", p. 325.

${ }^{82}$ Feria García y Arias Torres, "Un nuevo enfoque”, pp. 209-210. 
tienda en la puerta de Bibarrambla, se presentan en dicho pleito como garantía por parte de Leonor Martínez para pagar el censo adeudado a Gerónimo de Madrid. Se trata de tres documentos romanceados por Juan Rodríguez, escribano público, y don Miguel de León, veinticuatro de Granada, en mayo de 1524. Por una parte, los dos primeros documentos, fechados en 1484, hacen referencia a la compra y el pago que se realiza entre Mahamad, hijo de Hamete el Fordoz, y el mercader Abulcaçim. Nos proporcionan una rica información sobre la ubicación de la alhóndiga en el arrabal de Bibarrambla, en una intersección de calles, lindando al sur con la casa de San Lázaro y al este con el Zubayr o Zubayre, mientras que al norte y al oeste se encuentran dos calles. Por otra parte, la venta se produce entre Mahamad y Gonzalo Martínez y su mujer Ynés del Pulgar, en 1491. En ella se especifica como este inmueble contaba con un palomar que junto a "otras cosas" se incluían en dicha venta.

En la documentación cristiana recogida en el cuadro 01 hallamos 14 alhóndigas. El elevado número de las mismas nos lleva a pensar que en estos momentos la utilización del término alhóndiga como traducción de funduq. El primer establecimiento pertenece a la renta de la hagüela ${ }^{83}$ situada en la puerta del Albaicín. En la relación de los habices que pasaron de las mezquitas a las iglesias se citan 10 alhóndigas, de las cuales solo cuatro pertenecían a dichos habices. Una alhóndiga de Santa María de la $\mathrm{O}$, otra situada frente a la madraza, y una alhóndiga de cereros, formaban parte de los habices de la iglesia de Santa María de la O. La cuarta alhóndiga se encontraba dentro del conjunto de los habices de la iglesia de San Salvador. Resulta curioso que solo las dos mezquitas (posteriores iglesias) principales de la ciudad fueran las que tuvieran entre sus bienes este tipo de inmuebles comerciales. El resto aparecen de manera secundaria como límites o lindes de otros inmuebles: otra alhóndiga en la gallinería, a la salida de la puerta de Bibarrambla otra, la alhóndiga del bachiller Salazar, otra en la colación de San Salvador y otra en Rabadalhogeos, uno de los barrios que conformaba el gran arrabal del Albaicín. Los cuatro últimos edificios que se recogen en el cuadro 01 pertenecen al conjunto de habices que tras la conquista fueron dados al

${ }^{83} \mathrm{Al}$ igual que los habices esta renta también es de origen islámico, si bien plantea muchos más problemas en lo que a su definición se refiere. La renta de la hagüela era el pago que se realizaba por el uso de los hornos, molinos, tiendas y baños que pertenecían al patrimonio de la familia real nazarí. Véase González Sopeña, "Arabismos y fiscalidad", pp. 112-114. 
concejo de la ciudad. De estas, dos forman parte de los habices de la madraza: la alhóndiga donde ponen los lienzos los curanderos y la alhóndiga Çaida. Una es de los habices destinados al mantenimiento de los aljibes, la alhóndiga donde espadan el lino. El último ejemplo, la alhóndiga vieja del pescado, es mencionado como límite de otro inmueble ubicado en las cercanías del puente de los curtidores.

Además, debemos tener en cuenta las dos alhóndigas mencionadas en la minuta que transcribimos en el anexo 1.B. Ambos terminaron en manos de Fray Garçía Quixada, obispo de Guadix. El primer inmueble, en el que se centra el documento, fue comprado por Alonso Lobo, canónigo de la iglesia mayor de Guadix, a Abulcaçim Abendafa. Dicho edificio se ubicaba en "Biba Almazan" y tenía por linderos por la parte de abajo, la segunda alhóndiga (que había pertenecido a Mahoma Albarrani y ahora era del mencionado obispo), por la parte de arriba la calle mayor que va a la puerta de "Biba Almazan" y por delante con la calle que va a la plaza nueva de Bib Rambla.

\subsection{La alhóndiga como espacio fiscal}

Posteriormente se observa como este término hace referencia al mismo inmueble, pero también aludía al desempeño de funciones muy específicas, centradas en la fiscalidad y almacenamiento de las mercancías que llegaban a la ciudad en cuestión. Esta acepción se encuentra especialmente vinculada al trigo, como observamos en el resto del reino de Castilla ${ }^{84}$. En la capital granadina se identifica más de una, y cada una de las existentes estaría especializada en la recogida de tributo y almacenamiento de un producto, como nos mostró en su momento Trillo San José ${ }^{85}$, al mencionar la alhóndiga nueva o el corral del carbón, la casa del jabón, la alhóndiga del vino, del pescado, del lino, la açaquifa (como la alhóndiga del cuero), la alhóndiga Zayda de cristia$\operatorname{nos}^{86}$ (Figura 7), la de la especiería, así como la casa de la aduana de la

\footnotetext{
${ }^{84}$ Pereira Iglesias, "La alhóndiga cacereña", pp. 205-220; Gordo Peláez, "Pósitos, alhóndigas y alholíes”, pp. 102-114; Rowena Hernández-Múzquiz, "Pan y obras”, pp. 355-403.

${ }^{85}$ Trillo San José, "Modificaciones castellanas", pp. 27-40.

${ }^{86}$ En junio de 1498, el arzobispo de Granada, el corregidor Calderón, Hernando de Zafra, secretario de sus altezas, varios regidores de la ciudad, y Mahomad el Pequení, cadí mayor de los moros e almotacén, visitando las calles que habían de ensanchar para la ve-
} 
alcaicería. Esto también se refleja en los protocolos notariales de la capital granadina (cuadro 04), donde volvemos a encontrarnos la alhóndiga del vino, del pan, así como la alhóndiga de la especiería. El fuerte control sobre las mercancías se muestra en el hecho de que estas habían de pasar dos días en el interior de la alhóndiga antes de ser vendidas ${ }^{87}$. Debido a esa función fiscal estos espacios, generalmente, formarían parte de los bienes propios de los concejos, siendo estos sus propietarios y los encargados de arrendarlos ${ }^{88}$. Muy puntualmente estas alhóndigas fueron utilizadas como alojamiento. En Almería, la alhóndiga se utilizó en 1532 como aposento de los escuderos de las capitanías del conde de Chincón y de don Gerónimo de la Cueva ${ }^{89}$.

En general, la supresión de su función de hospedaje provocó la aparición de otros edificios independientes destinados a tal fin: los mesones. En el ejemplo de la capital granadina observamos tanto en los habices (cuadro 03) como en la documentación notarial (cuadro 05) que estos se centran especialmente en el arrabal islámico de Bibarrambla o colación de la Magdalena. Más concretamente 11 de los 23 mesones citados se encuentran en la zona: mesón de la Estrella, el de la Campana, el de Gómez de Santarem, el de Juan Rodríguez Dávila, el de los Correos, el de Alonso de Córdoba, el del Toro, el del Rastro y el de Diego Pavón. Situados en torno a la Calle Real, denominada posteriormente como calle de los Mesones (nombre que conserva hasta la actualidad), señalan la importancia de estos en esta zona de la ciudad. Los otros 12 mesones, el Alonso de Maute, el del doctor Alonso Mén-

nida de los reyes, el mencionado almotacén dio para la Alhóndiga Zayda de cristianos las casas de Haquén, cerca de la plaza del Hatabín (Moreno Trujillo, La memoria de la ciudad, p. 230). Sin embargo, sabemos que esa no fue su ubicación definitiva, ya que un mes más tarde, en julio, observamos que la esta alhóndiga se encuentra cerca de la plaza de Bibarrambla (Moreno Trujillo, La memoria de la ciudad, p. 237). Más exactamente junto a la puerta de Bibarrambla, lindando con casas del contador Ribadeneyra, la acequia de Darrillo, el Matadero y con el mesón de Baeça (Moreno Trujillo, Obra Sierra, Osorio Pérez, Los libros de rentas, p. 111, $\left.\mathrm{n}^{\circ} 41\right)$. Precisamente en la excavación realizada en el solar situado en la esquina entre calle Reyes Católicos y calle Mesones fueron excavados en el año 2012, los restos de un inmueble en el que se diferenciaron dos fases de ocupación. Una primera fechada en el s. XII-XIII, es decir, época almohade y los inicios de la nazarí. Y una segunda, situada cronológicamente en el s. XVI, precisamente esta fase se identifica con la mencionada alhóndiga Zaida (Arroyo Pérez et al., "Excavación arqueológica de urgencia en la alhóndiga Zayda", pp. 279-283).

${ }^{87}$ Ortega Cera, "Rentas mayores y menores", p. 293.

${ }^{88}$ Perdiguero Ayala y Pareja Pareja, "La reglamentación de la alhóndiga", pp. 281-291.

${ }^{89}$ Alcocer Martínez, Catálogo documental, pp. 159-162. 
dez de, el de los herederos de la condesa de Tamina, el de Pedro de Carmona, el de Andrés de Torres y el del Moral, el de Bartolomé González, se encuentran distribuidos por el resto de la ciudad. Por último, cabe destacar la construcción de un nuevo mesón extramuros de la Puerta de Elvira que pertenecía al jurado Pedro Hernández.

En esta situación dos ejemplos de la capital granadina, ilustran perfectamente el cambio de denominación de los espacios antes conocidos como fanādiq o alhóndigas. El primero se refiere a la alhóndiga que mencionan los documentos romanceados que adjuntamos en el anexo 1.A. Si mientras en el traslado que transcribimos observamos que al inmueble se le denomina alhóndiga, la cual poseía un palomar, en un memorial de los bienes adquiridos por Gonzalo Martínez e Ynes del Pulgar durante su matrimonio, contenido en el mismo pleito, no se menciona ninguna alhóndiga, pero si un mesón con un palomar. El segundo se refiere a una alhóndiga cuya principal función estaba relacionada con su uso como taller por parte de un grupo de artesanos, en concreto nos referimos a una alhóndiga donde se espadaba el lino según el apeo de $1506^{90}$, sin embargo en un apeo posterior $(1537)^{91}$, este mismo inmueble aparece como tarbea de espadar lino ${ }^{92}$. En ambos casos el cambio de denominación, está directamente vinculado a no desempeñar ninguna actividad de carácter fiscal.

La confusión con respecto a la utilización de ambos términos se agudiza cuando analizamos ejemplos relativos a ciudades de menor tamaño que la capital granadina. Esto se debe en primer lugar a la utilización de la palabra castellana alhóndiga, con los dos significados que hemos visto, es decir, como sinónimo del término árabe funduq, y como espacio dedicado a la recolección de los impuestos de las diversas mercaderías. En segundo lugar, por el hecho de que tanto el termino alhóndiga, como mesón se aplican al mismo espacio.

En el caso de Guadix se identifican dos alhóndigas. Ambas se reparten a las iglesias de esta ciudad: una en la plaza principal, y otra fuera de la Puerta de Baçamarín ${ }^{93}$. Posteriormente la primera se man-

${ }^{90}$ Moreno Trujillo, Obra Sierra y Osorio Pérez, Los libros de rentas, p. 41.

${ }^{91}$ Moreno Trujillo, Obra Sierra y Osorio Pérez, Los libros de rentas, p. 126, $\mathrm{n}^{\circ} 89$.

${ }^{92}$ Inmuebles compuestos por varias estancias e incluso varias plantas, principalmente ubicados en los arrabales, alquilados o acensuados por un grupo de artesanos, transformándolos en un lugar de trabajo colectivo.

${ }^{93}$ Asenjo Sedano, Repoblación, mercedes y reparto de propiedades, pp. 55-56. 
tiene como alhóndiga, mientras que la segunda pasa a denominarse como mesón ${ }^{94}$.

En otro ejemplo observamos que ambos términos (alhóndiga y mesón) suelen aplicarse para denominar al mismo espacio. En la ciudad de Loja, donde pese a utilizar uno y otro, podemos observar cierta diferenciación o referencia a un espacio concreto ya que se habla de "el mesón de la alhóndiga" el cual se encontraba vacío en 1517 al no haber sido arrendado ${ }^{95}$.

Sin duda, el ejemplo más complejo se encuentra en la ciudad de Baza. En el Repartimiento se cita,

Ay una casa que se llama "el alhóndiga" que es "un mesón donde se recogen las rentas" $"$.

El término mesón es utilizado para aclarar que es una alhóndiga, especificando que en esta se recogen las rentas, es decir, los tributos. Como tal solo se reconoce una, que es dada por merced a Pedro de $\mathrm{Araoz}^{97}$, mientras que el resto son mesones. Sin embargo, en la carta de los bienes otorgados al concejo de la ciudad aparece una casa-alhóndiga ${ }^{98}$, que tradicionalmente se interpreta como la misma que hemos mencionado anteriormente ${ }^{99}$.

Sin embargo, pensamos que se trata de dos edificios diferentes, lo que supondría la existencia de dos fanādiq en la Baza islámica. Dos escrituras, una de arrendamiento ${ }^{100} \mathrm{y}$ otra de traspaso de censo ${ }^{101}$, ambas

${ }^{94}$ Asenjo Sedano, Repoblación, mercedes y reparto de propiedades, p. 64.

${ }^{95}$ Archivo Histórico Municipal de Loja, libro de cabildos 1517-1527, fol. 26r.

${ }^{97}$ Miralles Lozano, Repartimiento de Baza, vol. 2, p. 9.

${ }^{97}$ Miralles Lozano, Repartimiento de Baza, vol. 2, pp. 125-128; Ladero Quesada, "Mercedes reales en Granada", pp. 355-424, espec. p. 376; AGS, CCA, Libro 254, fol. 88v.

${ }^{98}$ Miralles Lozano, Repartimiento de Baza, vol. 3, p. 848.

${ }^{99}$ Miralles Lozano, Repartimiento de Baza, vol. 1, pp. 206 y 223. Tristán García, "De Basta a Baza", p. 45.

${ }^{100}$ A.P.N.Gr., Escribanía de Juan de Ahedo, prot. 14 (Baza), fol. 496r-496v. 1532, febrero, 26. Baza. Carta de arrendamiento: "Juan de Araoz, secretario del consejo de sus majestades, vecino e regidor de Baza, arrendó a Alonso Hernández de Baeza, la alhóndiga-mesón de los nuevamente convertidos, en el Barrionuevo con los derechos e libertades a ella pertenecientes con que está este arrendamiento, una tienda donde pesan carnes que está a la puerta de la dicha alhóndiga, así mismo una casa pequeña que está incorporada con la dicha alhóndiga e se manda por de fuera que suelen los alhondigueros alquiler por un año 5.250 maravedís cada mes".

${ }^{101}$ A.H.M.B., libro de censos 1523-1629, fol. 125r-128r. 1532, mayo, 10. Baza. Carta de traspaso de censo. El alcalde mayor y los regidores de la ciudad de Baza acordaron que 
fechadas en 1532, nos llevan a defender esta información. En primer lugar, por la procedencia de los documentos, la escritura de arrendamiento proviene del Archivo de Protocolos Notariales, mientras que la segunda viene del Archivo Histórico Municipal. Si bien, es cierto que la procedencia de los documentos no es un indicativo demasiado fiable de que hablemos de dos inmuebles distintos, ya que hay casos de inmuebles que son dados a censo por parte del Concejo y posteriormente aparecen en los registros notariales dados en arrendamiento o subarriendo, apareciendo en ambos documentos la misma persona. Sin embargo, en este caso suceden dos hechos que no coinciden: en primer lugar, que la escritura de traspaso de censo es unos meses posterior (mayo, 1532) a la de arrendamiento (febrero, 1532); y en segundo lugar, que ningún de los que intervienen en ambos casos se repiten. Es decir, en la escritura de arrendamiento Juan de Araoz, secretario del consejo de sus majestades, vecino y regidor de Baza, arrendó a Alonso Hernández de Baeza, la alhóndiga mesón de los nuevamente convertidos, en el Barrionuevo, mientras que en la carta de traspaso de censo, Rodrigo Serrano traspasó el censo a Alonso de Vayona con el beneplácito del alcalde mayor y los regidores de la ciudad de Baza, ya que el mesón-alhóndiga traspasado formaba parte de la renta de propios. Por último, en relación a estas alhóndigas, es la propia denominación que se emplea para referirse a las mismas, mientras en la escritura de arrendamiento aparece como alhóndiga-mesón dando preeminencia a la función fiscal y de almacenamiento frente a la de alojamiento, en el caso de la escritura de traspaso aparece denominada como mesón-alhóndiga, asumiendo un papel principalmente de alojamiento.

\section{Conclusiones}

El funduq es un edificio de planta cuadrada o rectangular, de tamaño variable al que se puede acceder directamente desde la calle principal, o bien de manera indirecta por un lateral o un adarve que forma parte del inmueble. Cuenta con un patio, espacio central en torno al cual se

por cuanto Rodrigo Serrano tenía a censo el mesón-alhóndiga de la dicha ciudad que es de las rentas de propios por 6.000 maravedíes anuales pidió traslado de censo a Alonso de Vayona. 
organizaba el edificio, en él encontramos un pozo, fuente o alberca. En torno a esta área abierta transcurre un andén que permite la entrada a las diferentes estancias. Estas pueden estar distribuidas en uno o más pisos, con un tamaño similar entre las mismas. Las principales funciones son de hospedaje y almacenamiento, pero también se han identificado cuadras o establos, tiendas y talleres. Asimismo, debemos señalar que eran lugares utilizados por funcionarios para recoger impuestos, regular la distribución de algunos bienes y, en definitiva, controlar las actividades de los mercaderes.

Este tipo de inmuebles fueron evolucionando tanto en territorio islámico como cristiano. Aunque estas nuevas instituciones compartían algunas características funcionales y estructurales, también adquirieron rasgos propios.

Por un lado, el fondaco, un espacio arrendado o donado por las autoridades musulmanas a las comunidades cristianas de mercaderes que cumplía con todas las necesidades de estos últimos (religiosas, sociales y económicas) provocando que lo que inicialmente habría de identificarse con un edificio, conformara un conjunto de establecimientos. Su principal particularidad reside en crear un área de exención donde no se reconoce la soberanía musulmana, sino la del país de origen de los mercaderes.

Por otro, la alhóndiga, la cual hemos analizado a través de los datos conservados en la documentación castellana generada tras la conquista del emirato nazarí. En un primer momento, ambas palabras designan un mismo espacio que cumple con similares funciones (como se refleja en los documentos editados y en el cuadro 01 del anexo). Sin embargo, posteriormente se observa como la primera se convierte en una institución con unas funciones específicas de almacenamiento y recogida de impuestos de determinadas mercancías. Por otro lado, los establecimientos que mantienen su actividad como lugares destinados al hospedaje de viajeros pasan a denominarse mesón. Mientras que en Granada ambos términos designan inmuebles diferentes, en ciudades de menor tamaño genera cierto desconcierto con el término mesón, al ser utilizados ambos para referirse al mismo espacio. 


\section{Figuras}
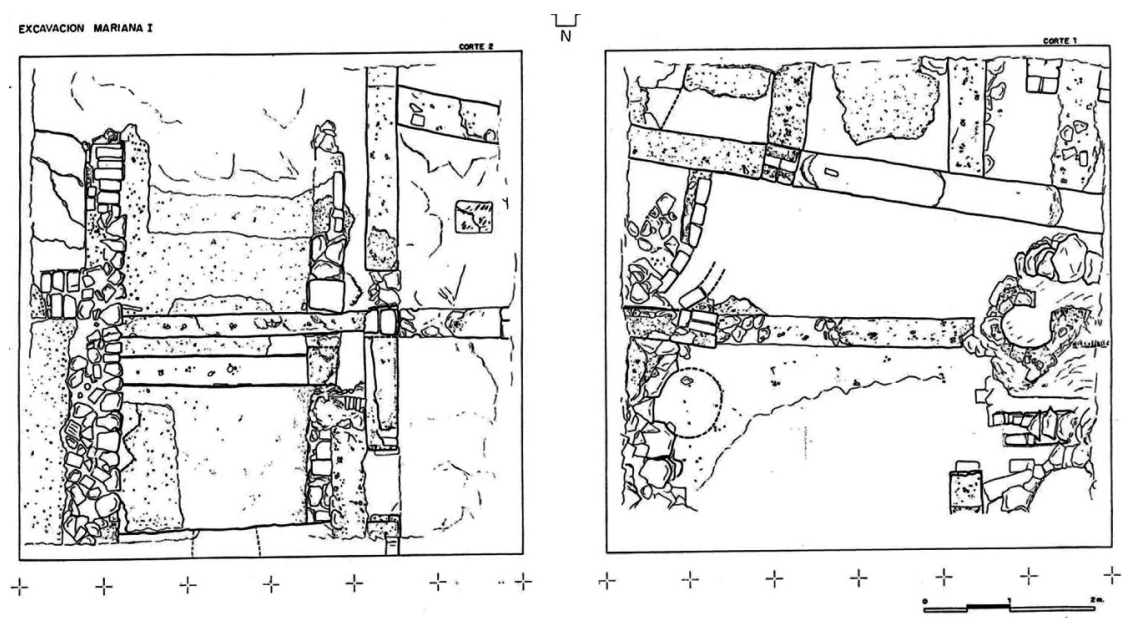

Figura 1. Estructuras documentadas en la Calle Mariana, Almería ${ }^{102}$.

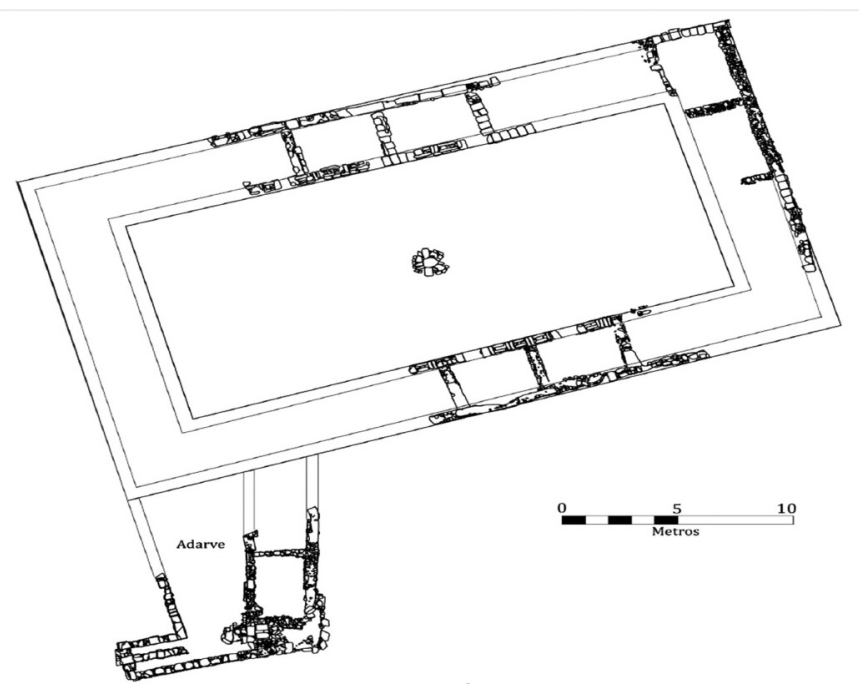

Figura 2. Funduq excavado en la Manzana 14 del Plan Parcial O-7 de Córdoba ${ }^{103}$.

${ }^{102}$ García López, Cara Barrionuevo, Flores Escobosa y Morales Sánchez, "La organización de espacios", p. 14.

${ }^{103}$ Clapés Salmoral, "La actividad comercial de Córdoba", p. 239. 


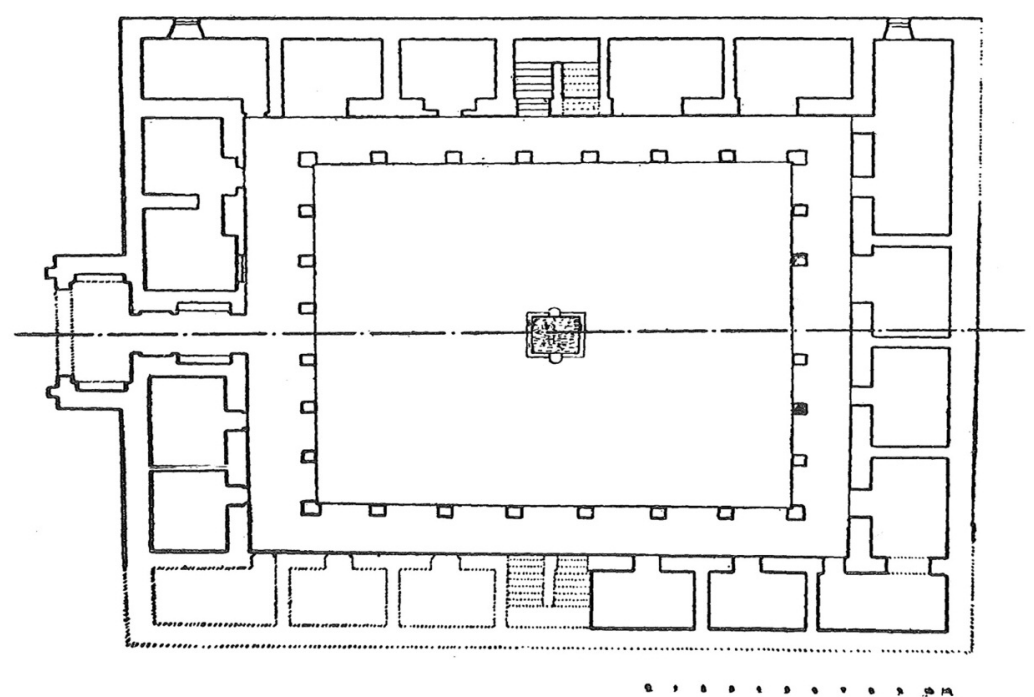

Figura 3. Corral del Carbón o funduq al-ŶYadìda, Granada ${ }^{104}$.

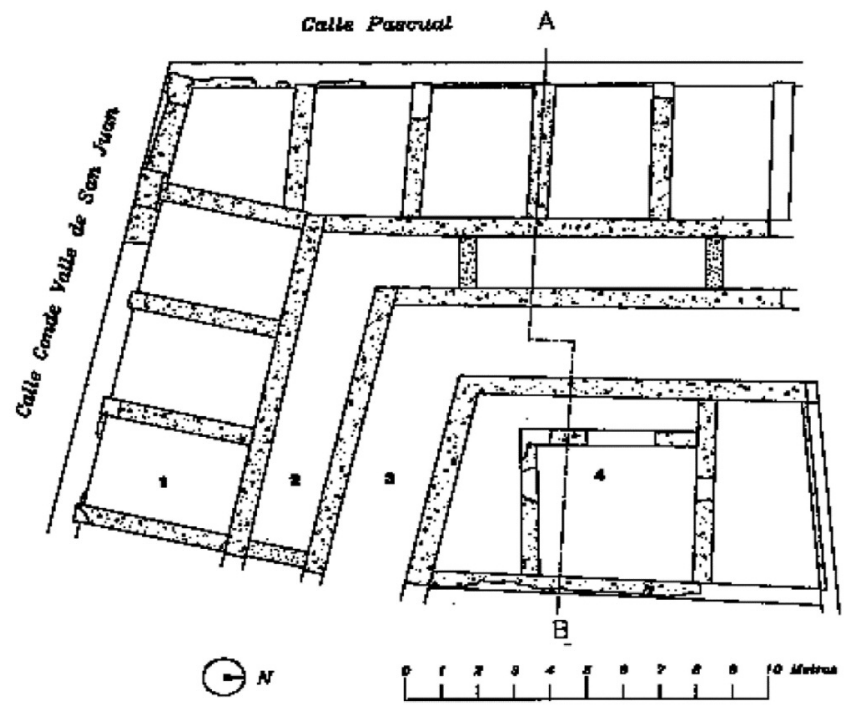

Figura 4. Calle Conde Valle de San Juan esquina calle Pascual, Murcia ${ }^{105}$.

${ }^{104}$ Torres Balbás, "Las alhóndigas hispanomusulmanas", p. 464.

${ }^{105}$ Ruiz Parra, "Excavaciones arqueológicas en el solar", p. 421. 


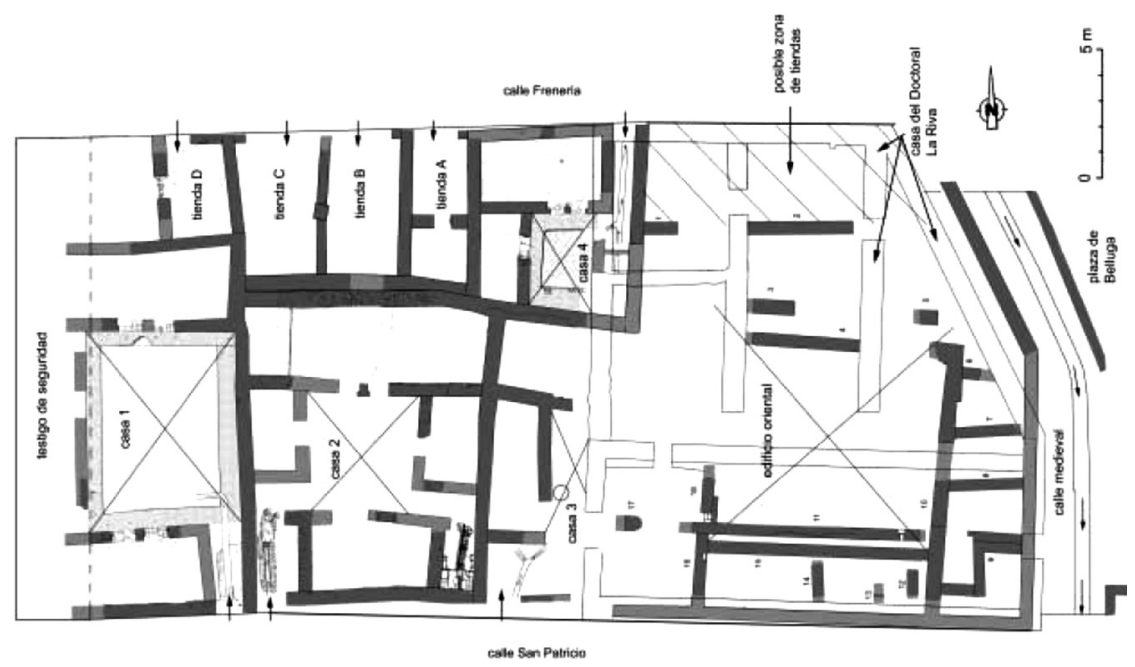

Figura 5. Solar excavado en la Plaza Belluga, Murcia ${ }^{106}$.

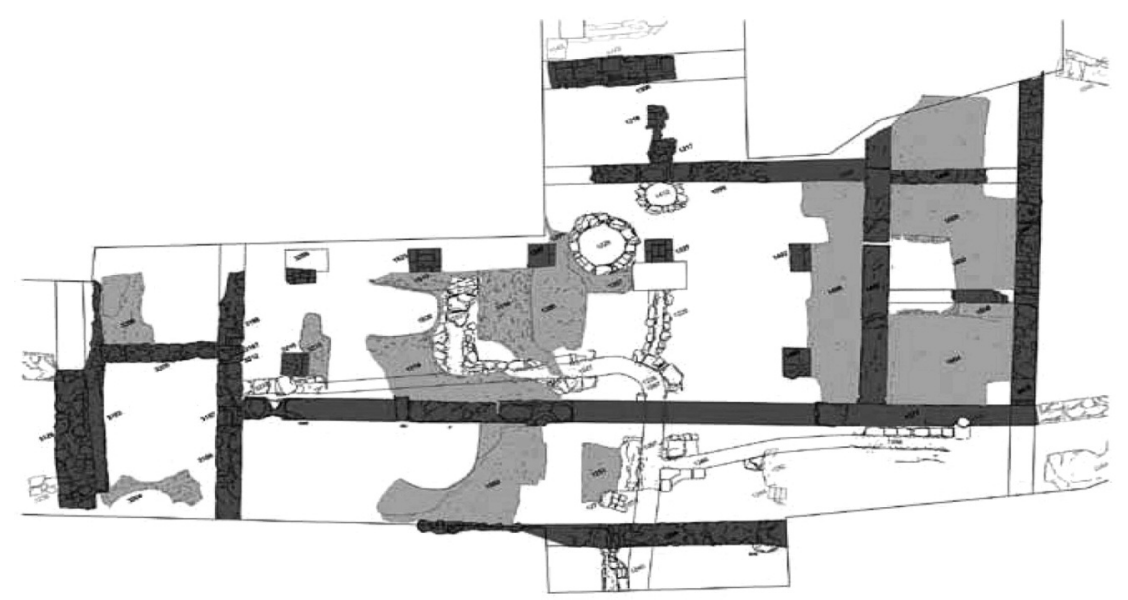

Figura 6. Funduq identificado en las excavaciones arqueológicas de la calle Corretgeria, Valencia ${ }^{107}$.

${ }^{106}$ Jiménez Castillo y Navarro Palazón, "Casas y tiendas", p. 494.

${ }^{107}$ Martí Oltra y Burriel Alberich, "Comerciar en tierra extraña", p. 57. 


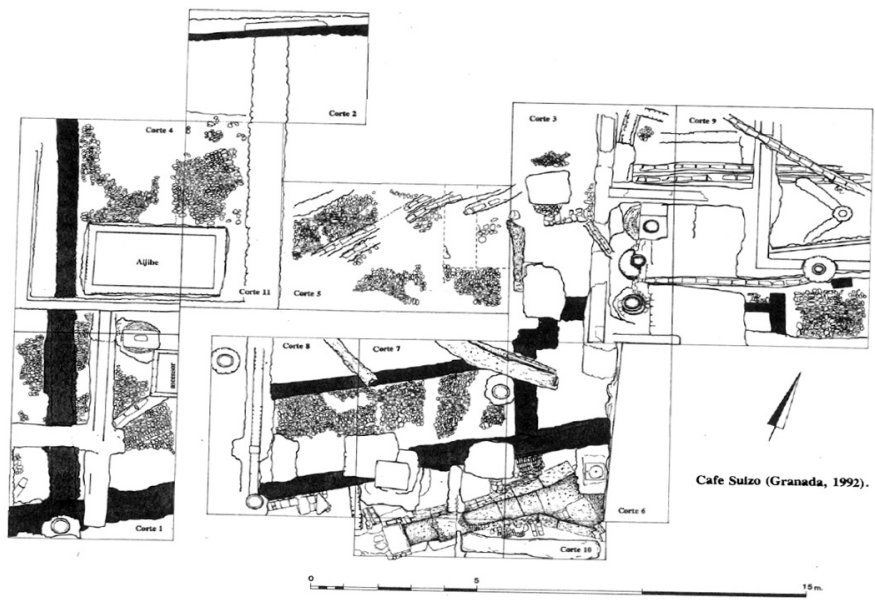

Figura 7. Alhóndiga Zayda, Granada ${ }^{108}$.

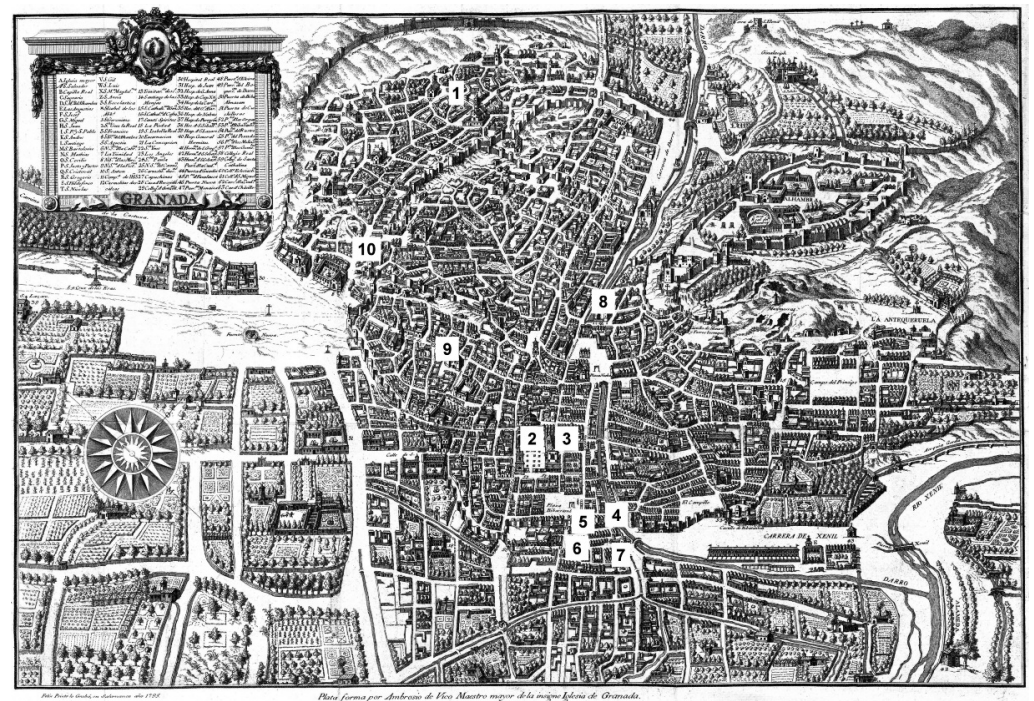

Figura 8. Plataforma de Ambrosio de Vico, Granada ${ }^{109}$. Principales ubicaciones de las alhóndigas citadas en el texto: 1) Colación de San Salvador, Albaicín; 2) Colación Santa María de la O; 3 ) Madraza; 4) Puente de los Curtidores; 5) Puerta de Bibarrambla; 6) Calle de los Mesones, Arrabal de Bibarrambla/Colación de la Magdalena; 7) Alhóndiga Zayda; 8) Colación de Santa Ana; 9) Calle Elvira; 10) Cuesta de Alhacaba.

${ }^{108}$ Arroyo Pérez et al., "Excavación arqueológica de urgencia en la alhóndiga Zayda", p. 280.

${ }^{109}$ A.H.M.Gr., Planos, 2. 


\title{
ANEXOS
}

\section{Documentos}

\author{
Documento A
}

1524, mayo, 31. Granada

Traslado romanceado de tres escrituras relacionadas con compra, pago y venta de una alhóndiga situada en el arrabal de Bibarrambla, contenidas en el pleito entre Leonor Martínez, hija y heredera de Gonzalo Martínez, y Gerónimo de Madrid, abad de Santa Fe, por el pago de un determinado censo.

\section{A.R.Ch.Gr., caja 5417, pieza 5}

Este traslado bien e fielmente sacado de dos cartas de vendida e de vna carta de pago escripta al pie de vna dellas en letra aráviga la vna escripta en papel e la otra en pargamino de cuero, firmadas e çiertos alfaquíes escriuanos públicos sigund por ellas parescía su tenor de las quales tornadas en lengua castellana vna en pos de otra diz en en esta guisa:

Con el nombre de dios piadoso e misericordioso compró el honrado Mahamad, hijo de Hamete el Fordoz, de su conpanero el mercader honrado Abulcaçim, hijo de Mahamad Abenhador, la vna mitad del alhóndiga que está en el arrabal de Bibarrambla uno de los arrabales de Granada en conpañía del comprador con la otra mitad e con esta conpra se le amplio todo,que alinda por la parte del mediodía con la casa de Sant Lázaro, por la parte del çierço con la calle e por la parte del levante con el zubayr e por la parte del poniente con la calle; con los derechos de la dicha mitad e de vedamientos entradas e salidas con todas sus pertenençias, conpra cumplida por preçio e contía la mitad susodicha de setenta doblas de oro de la moneda de almoeted ${ }^{110}$ del cuño nuevo, e le dio en pago de veynte doblas de oro de las susodichas la vna mitad del christiano que estaba en conpanía entrellosde por medio e se llama Alonso se le amplió el señorio del christiano e le dio por / libre de las veynte doblas suso dichas e lo

${ }^{110}$ Expresión traducida erróneamente en las escrituras romanceadas. Se traduce en este caso por "... doblas de oro de la moneda de almoeted..." cuando su traducción correcta sería "dinar de oro al cambio de plata acostumbrado". Miguel Jiménez Puertas, "La evolución del sistema monetario nazarí", Gaceta numismática, n 150 (septiembre, 2003), pp. $31-49$, espec. 33 . 
restante lo a de pagar cada que se lo demandare. E por esto se le cumplió al comprador el señorio de lo que compro entera e cunplidamente por la ley e costumbre en ello e se obligo al saneamiento después que lo vieron e reconoçieron e supieron lo que hazian e asy lo otorgaron ante quien lo conoció, estando sanos e con salud bastante, a tres días de la luna de mahoram prinçipio del año de ochoçientos e noventa. E asy lo firmaron de sus nombres dos alfaquíes escriuanos públicos.

Los loores a dios. Reçebió el vendedor del conprador susodicho todo lo que le restaba deviendo del preçio e se otorgo por contento dello, porque lo reçibió cumplidamente e supo lo que hazia, e asy lo otorgo ante quien lo conoçio con salud bastante, a dos días de la luna de rabealagual año de ochoçientos e noventa. E asy lo fyrmó de su nombre un alfaqui escriuano publico.

Concuerda la fecha de las cartas de vendida e de pago de suso contenidas con el año del naçimiento de nuestro saluador Ihesuchristo de mill e quatroçíentos e ochenta y quatro años.

Los loores a dios altísimo. Vendió el honrado noble Mahamad, hijo de Hamete el Fordoz, a los christianos, marido y mujer, Gonçalo Martinez escriuano del alcalde juez // de Granada e Ynes de Pulgar, ygualmente e de por medio entrellos, toda el alfóndiga questa en el arrabal de Bibarrambla vno de los arrabales de Granada que alinda por la parte del mediodía con la casa de Sant Lazaro e por la parte del çierço con la calle e por la parte del levante con el Zubayre e por la parte del poniente con la calle; con sus derechos e devedamientos e con todas sus pertenençias e con el palomar e palomas e otras cosas que en él están. Venta cunplida por preçio e contia de seysçientos e treynta pesantes de plata, de los de a diez dineros, que los recibió el vendedor juntamente e pasaron a su mano e dio por quitos a los compradores suso dichos, finiquito cumplido, e por esto se amplió a los compradores el señorio de lo que compraron entera e cunplidamente por la ley e costumbre en ello e se obligó al saneamiento después que lo vieron e reconoçieron e fueron contentos e supieron lo que hazian. E asy lo otorgaron ante quien los conoçió estando sanos e con salud bastante, a tres días de la luna de dulhija fyn del año de ochoçientos e noventa e siete. E asy lo firmaron de sus nombres tres alfaquíes escriuanos públicos.

Concuerda la fecha desta carta de vendida postrera de suso contenida con el año del naçimiento de nuestro salvador Ihesuchristo de mill e quatroçientos e noventa e vn años./ 
Fecho e sacado fue este dicho traslado de las dichas cartas de vendida e carta de pago en la muy noble nombrada e gran çibdad de Granada, a treynta e vn días del mes de mayo año del naçimiento de nuestro salvador Ihesuchristo de mill e quinientos e veynte e quatro años. Testigos que fueron presentes a ver, sacar, leer e conçertar este dicho traslado con las dichas cartas de arávigo originales, Diego de Vera escriuano de su magestad e Juan el Bayni, vezinos desta dicha çibdad de Granada.

(Firma y rúbrica en árabe)

(Firma y rúbrica en árabe)

E yo Juan Rodríguez, escriuano de sus çesarea católicas magestades e su escriuano e notario público en la corte e en todos los sus reynos e senorios, romançé con don Miguel de Leon, veynte e quatro de Granada, estas cartas de suso contenidas, e presente fuy en uno con los dichos testigos a las leer e conçertar con las dichas cartas originales e van firmadas de mi nombre e lo escriví e por ende fiz aquí este myo signo (signo) en testimonio de uerdad.

Juan Rodríguez, escriuano (firma y rúbrica)

\section{Documento B}

1498, mayo, 10. Guadix

Minuta de una escritura donde Fray Garçía Quixada, obispo de Guadix, recibe como pago de una deuda de 340 reales del canónigo Alonso Lobo, una alhóndiga situada en la puerta de Bāb al-Mașda, que el mencionado Alonso Lobo había comprado con el dinero prestado.

A.M.H.P.N.G., protocolo de Alonso de las Casas XV-1, $\mathrm{n}^{\circ}$ 1, documento suelto $\mathrm{n}^{\mathrm{o}} 11$

En diez días del mes de mayo de XCVIII años otorgó el benerable Alonso Lobo,canónigo de la iglesia mayor desta dicha çibdad de Guadix, e dixo que por quanto el muy reverendo señor don fray Garçía Quixada, obispo de la dicha çibdad de Guadix, ovo conprado por el dicho canónigo Alonso Lobo e para él en la çibdad de Granada vna casa de alhóndiga questa a Biba Almazan de vn moro que se llamó Albucaçim Abendafa, la qual conpro por trezientos e quarenta reales; la qual dicha casa de alhóndiga ha por linderos del cabo de [a]baxo vna alhóndiga vieja que fue de Mahoma Albarrani y es agora del dicho señor obispo, y del cabo de arriba la calle mayor que va a la dicha puerta de Biba Almazan y vna al- 
macería derrocada, y por del[ante] la puerta la çerca de la çibdad y calle que va a la plaza nueva de Bib Rambla. E porque el dicho señor obispo le ovo prestado al dicho canó[nigo] Alonso Lobo e pago por él los dichos trezientos e quarenta reales [...] le deue e no se los a pagado e por nesçesydad que tiene no se los a p[agado ni] puede pagar, que porque élse partia desta dicha cibdad e yglesia [no] sabe quando bolbera a ella, queriendo satisfaser e pagar los [dichos] trezientos e quarenta reales al dicho señor obispo e no tenyendo o [...] mas a la mano con que le pagar los dichos reales pidió por [merçed] al dicho señor obispo tomase en preçio dellos la dicha casa de [alhóndiga] que asy conpro para el dicho canónigo, como dicho es, que el çedia e [traspasaba] e çedió e traspaso en el dicho señor obispo la dicha casa de alhóndiga en hequivalençia de los dichos trezientos e quarenta reales que le presto [para] las conprar para él en el dicho señor obispo, para que sean suya[s] para él e para sus herederos e para quien el quisyere e por bi[en] toviere, para syempre jamás, para que las pueda vender, enpe[ñar], dar, donar, trocar e canbiar e hacer dellas e en ellas como cosa suya propia conprada e avida por sus propios dineros. E para que las tenga por justo e derecho titulo dixo que para ello le d[ava] e entregaua las cartas de compra que de la dicha casa de alhóndiga tiene, e que sy mas valen o valiere de los dichos trezientos e quarenta reales que le fazia e fizo gracia e donaçión de la demasya./ E quanto a esta donaçión renunçió la ley de los quinientos sueldos etc., e desapoderose del señorío e posesyón e propiedad de las dichas casas de alhóndiga e la renunçio en el dicho señor obispo, e que le daua e dio poder para la tomar por su propia avtoridad para que las pueda vender e hacer dellas lo que quisyere e por bientouiere, segund dicho es, e obligó a su presona e bienes de no yr contra esta traspasaçion que le fase de la dicha casa de alhóndiga,él ni otro por él, sopena de le pagar los dichos trezientos e quarenta reales con el doblo e mas los reparos e hedefiçios que en la dicha alhóndiga oviere fecho e costas e daños e menos cabos que sobre ellos se le recreçieren, etc. Para lo qual todo que suso dicho es obligó el dicho canónigo Alonso Lobo su presona e bienes, e renunçió todas e qualesquier leyes e fueros e derechos e plazos e términos e todas las otras cosas de que se podría aprouechar etc., e dio poder a las justiçias eclesyásticas e otorgo carta en forma etc.

Testigos: Juan de Aguylar, notario de la dicha iglesia, e Fernando Ruys, clérigo de Santa Maria, e Francisco de Mata, hijo de Diego de Mata, vecino de Baeça. 
DEL FUNDUQ A LA ALHÓNDIGA: UN ESPACIO ENTRE El EMIRATO NAZARÍ Y EL REINO DE GRANADA...345

\section{Cuadros}

Cuadro 01. Alhóndigas en los bienes habices y hagüela.

\begin{tabular}{|c|c|c|c|c|}
\hline $\mathbf{N}^{0}$ & Alhóndiga & Propiedad & Ubicación & Referencia \\
\hline 1 & Alhóndiga & Hagüela & Puerta del Albaicín & HAG1505 ${ }^{111}$ p. 174 \\
\hline 2 & Alhóndiga de Sta. M. ${ }^{a}$ de la $\mathrm{O}$ & $\begin{array}{l}\text { Habiz de Sta. M. }{ }^{\text {a }} \\
\text { de la } \mathrm{O}\end{array}$ & $\begin{array}{l}\text { En una de las calles } \\
\text { que desembocaban en } \\
\text { la plaza donde se si- } \\
\text { tuaba la madraza }\end{array}$ & $\begin{array}{l}\text { HAB } 1505^{112} \text { p. } 28 \mathrm{n}^{0} \\
10 \\
\text { HAB } 1505 \text { p. } 30 \mathrm{n}^{0} 29\end{array}$ \\
\hline 3 & $\begin{array}{l}\text { Alhóndiga de los zurranderos } \\
\text { Alhóndiga donde ponen los } \\
\text { lienzos los curanderos }\end{array}$ & $\begin{array}{l}\text { Habiz de la ma- } \\
\text { draza }\end{array}$ & $\begin{array}{l}\text { Frente a Sta. M. }{ }^{\text {a de la }} \\
\text { O }\end{array}$ & $\begin{array}{l}\text { HAB1505 p. } 28 \mathrm{n}^{0} 11 \\
\text { HAB1506 } 113 \text { p. } 36\end{array}$ \\
\hline 4 & Alhóndiga & $\begin{array}{l}\text { Habiz de Sta. M. }{ }^{\text {a }} \\
\text { de la } \mathrm{O}\end{array}$ & $\begin{array}{l}\text { Enfrente de la ma- } \\
\text { draza }\end{array}$ & HAB1505 p. 31 n $^{0} 32$ \\
\hline 5 & Alhóndiga & & $\begin{array}{l}\text { A la salida de la puerta } \\
\text { de Bibarrambla en la } \\
\text { calle de los arados }\end{array}$ & HAB1505 p. $32 \mathrm{n}^{0} 36$ \\
\hline 6 & Alhóndiga de cereros & $\begin{array}{l}\text { Habiz de Sta. M. }{ }^{a} \\
\text { de la O (la mitad) }\end{array}$ & $\begin{array}{l}\text { En la calle que va a } \\
\text { Sta. M.' de la } \mathrm{O} \text {, sa- } \\
\text { liendo de los tintore- } \\
\text { ros a la mano } \\
\text { izquierda }\end{array}$ & HAB1505 p. $33 n^{\circ} 45$ \\
\hline 7 & Alhóndiga & & En la gallinería & HAB1505 p. $128 \mathrm{n}^{\circ} 6$ \\
\hline 8 & $\begin{array}{l}\text { Alhóndiga del bachiller Sala- } \\
\text { zar }\end{array}$ & & $\begin{array}{l}\text { Colación de la Mag- } \\
\text { dalena }\end{array}$ & HAB1505 p. $161 \mathrm{n}^{\circ} 1$ \\
\hline 9 & Alhóndiga & & $\begin{array}{l}\text { Colación de San Sal- } \\
\text { vador }\end{array}$ & HAB1505 p. $164 \mathrm{n}^{\circ} 12$ \\
\hline 10 & Alhóndiga & & Rabadalhageos & HAB1505 p. $165 \mathrm{n}^{0} 27$ \\
\hline 11 & Alhóndiga & $\begin{array}{l}\text { Habiz de San Sal- } \\
\text { vador }\end{array}$ & Colación de Sta. Ana & HAB1505 p. $169 \mathrm{n}^{\circ} 60$ \\
\hline 12 & Alhóndiga vieja del pescado & & $\begin{array}{l}\text { Cercano al puente de } \\
\text { los curtidores }\end{array}$ & HAB1506 p. 35 \\
\hline 13 & Alhóndiga Çayda & $\begin{array}{l}\text { Habiz de la Ma- } \\
\text { draza (las tiendas } \\
\text { de su interior) }\end{array}$ & & HAB1506 p. 37 \\
\hline 14 & Alhóndiga donde espadan el lino & Habiz de los aljibes & En la Alacaba & HAB1506 p. 41 \\
\hline
\end{tabular}

${ }^{111}$ La abreviatura HAG1505 hace referencia Moreno Trujillo, Obra Sierra, Osorio Pérez, Los libros de rentas municipales, pp. 147-184.

${ }^{112}$ HAB1505: Villanueva Rico, Habices de las mezquitas.

${ }^{113}$ HAB1506: Moreno Trujillo, Obra Sierra y Osorio Pérez, Los libros de rentas municipales, pp. 31-92. 
Cuadro 02. "Casas" en los bienes habices.

\begin{tabular}{|c|c|c|c|c|}
\hline $\mathbf{N}^{0}$ & Casas & Propiedad & Ubicación & Referencia \\
\hline 1 & Casa de cereros & Habiz Abarrasin & En los tintoreros & HAB $1503^{114}$ p. $124 \mathrm{n}^{0} 116$ \\
\hline 2 & $\begin{array}{l}\text { Casa donde bruñen los } \\
\text { lienzos }\end{array}$ & $\begin{array}{l}\text { Habiz de Sta. } M^{\mathrm{a}} \text { de } \\
\text { la } \mathrm{O}\end{array}$ & $\begin{array}{l}\text { En dar Balcata, que es } \\
\text { la callejuela que va de } \\
\text { Sta. M. de la } \mathrm{O} \text { al } \\
\text { pilar de los tintoreros }\end{array}$ & HAB1505 p. $38 \mathrm{n}^{0} 77$ \\
\hline 3 & Casa de cerveros & Habiz de San Andrés & $\begin{array}{l}\text { Colación de San An- } \\
\text { drés }\end{array}$ & HAB1505 p. 79 n $^{\circ} 21$ \\
\hline 4 & Casa de espadadores & $\begin{array}{l}\text { Habiz de San Salva- } \\
\text { dor }\end{array}$ & $\begin{array}{l}\text { Colación de San Sal- } \\
\text { vador }\end{array}$ & HAB1505 p. 175 n $^{\circ} 113$ \\
\hline 5 & Casa caída de espadadores & Habiz de San Blas & Colación de San Blas & HAB1505 p. $179 \mathrm{n}^{0} 11$ \\
\hline
\end{tabular}

Cuadro 03. Alhóndigas en los protocolos notariales.

\begin{tabular}{|c|l|l|l|l|}
\hline $\mathbf{N}^{\mathbf{1}}$ & \multicolumn{1}{|c|}{ Alhóndiga } & Propiedad & \multicolumn{1}{|c|}{ Ubicación } & \multicolumn{1}{|c|}{ Referencia } \\
\hline 1 & Alhóndiga & & & PRO-G ${ }^{115}$ pp. 246-247 \\
\hline 2 & $\begin{array}{l}\text { Alhóndiga de la } \\
\text { especiería }\end{array}$ & & & PRO-G pp. 528-529 \\
\hline 3 & Alhóndiga del vino & & $\begin{array}{l}\text { Colación de la } \\
\text { Magdalena }\end{array}$ & PRO-G p. 1272 \\
\hline 4 & Alhóndiga del pan & & $\begin{array}{l}\text { Colación de la } \\
\text { Magdalena }\end{array}$ & PRO-G pp. 1282-1283 \\
\hline 5 & Alhóndiga de... & & $\begin{array}{l}\text { Colación de } \\
\text { San Gil }\end{array}$ & $\begin{array}{l}\text { A.H.P.Gr., Escribanía de } \\
\text { Francisco Muñoz, prot. 14 } \\
\text { (Granada), fol. 331r-332r }\end{array}$ \\
\hline 6 & Alhóndiga & $\begin{array}{l}\text { Miguel } \\
\text { el Mantaf }\end{array}$ & $\begin{array}{l}\text { Debajo de } \\
\text { Bibarrambla }\end{array}$ & $\begin{array}{l}\text { A.H.P.Gr. Escribanía de } \\
\text { Gonzalo Quijada, prot. 19 } \\
\text { (Granada), fol. 351v- 352v }\end{array}$ \\
\hline 7 & Alhóndiga & & Cabe el carbón & $\begin{array}{l}\text { A.H.P.Gr., Escribanía de } \\
\text { Gonzalo Quijada, prot. 26 } \\
\text { (Granada), fol. 442v- 443v }\end{array}$ \\
\hline 8 & $\begin{array}{l}\text { Alhóndiga de } \\
\text { moriscos }\end{array}$ & & $\begin{array}{l}\text { Colación de la } \\
\text { Magdalena }\end{array}$ & $\begin{array}{l}\text { A.H.P.Gr., Escribanía de } \\
\text { Diego Gutiérrez, prot. 30 } \\
\text { (Granada), fol. 81r -82v }\end{array}$ \\
\hline
\end{tabular}

${ }^{114}$ HAB1503: Hernández Benito, La Vega de Granada.

115 PRO-G: Obra Sierra, Catálogo de protocolos. 
Cuadro 04. Mesones en los bienes habices.

\begin{tabular}{|c|l|l|l|}
\hline $\mathbf{N}^{\mathbf{0}}$ & \multicolumn{1}{|c|}{ Mesón } & \multicolumn{1}{c|}{ Ubicación } & \multicolumn{1}{c|}{ Referencia } \\
\hline 1 & Mesón de los correos & & HAB1503 p. $118 \mathrm{n}^{\mathbf{0}} 47$ \\
\hline 2 & $\begin{array}{l}\text { Mesón de los herederos de } \\
\text { Francisco Núñez }\end{array}$ & & $\begin{array}{l}\text { HAB1503 p. } 120 \mathrm{n}^{\mathrm{o}} 73 \\
\text { HAB1505 p. } 96 \mathrm{n}^{\circ} 11\end{array}$ \\
\hline 3 & Mesón del bachiller Salazar & Calle Elvira & HAB1505 p. $85 \mathrm{n}^{\mathrm{o}} 75$ \\
\hline 4 & Mesón de Pedro de Úbeda & Colación de Santiago & HAB1505 p. $91 \mathrm{n}^{\mathrm{o}} 7$ \\
\hline 5 & Mesón de Pedro Montero & & HAB1505 p. $97 \mathrm{n}^{\mathrm{o}} 12$ \\
\hline 6 & Mesón de la Campana & $\begin{array}{l}\text { Colación de la Magda- } \\
\text { lena }\end{array}$ & HAB1505 p. $161 \mathrm{n}^{\circ} 1$ \\
\hline 7 & Mesón de Juan de Soria & Calle Elvira & HAB1506 pp. $42-43$ \\
\hline
\end{tabular}

Cuadro 05. Mesones en los protocolos notariales.

\begin{tabular}{|l|l|l|l|l|}
\hline \multicolumn{1}{|c|}{$\mathbf{N}^{\mathbf{0}}$} & \multicolumn{1}{|c|}{ Mesón } & \multicolumn{1}{c|}{ Propiedad } & \multicolumn{1}{c|}{ Ubicación } & \multicolumn{1}{c|}{ Referencia } \\
\hline 1 & $\begin{array}{l}\text { Mesón de la } \\
\text { Estrella }\end{array}$ & Pedro Fernández & $\begin{array}{l}\text { Colación de la } \\
\text { Magdalena }\end{array}$ & $\begin{array}{l}\text { PRO-G pp. 4-5 } \\
\text { A.H.P.Gr., Escribanía de Gonzalo } \\
\text { Quijada, prot. 19 (Granada), } \\
\text { fol. 307v - 310r }\end{array}$ \\
\hline 2 & Mesón & $\begin{array}{l}\text { Doctor Alonso } \\
\text { Méndez de Salazar }\end{array}$ & Puerta de Elvira & PRO-G pp. 750-751 \\
\hline 3 & Mesón & Gómez de Santarem & $\begin{array}{l}\text { Colación de Sta. } \\
\text { M. }{ }^{2} \text { Magdalena }\end{array}$ & PRO-G p. 961 \\
\hline 4 & Mesón & $\begin{array}{l}\text { Juan Rodríguez } \\
\text { Dávila }\end{array}$ & $\begin{array}{l}\text { Colación de Sta. } \\
\text { M. }{ }^{\text {a Magdalena }}\end{array}$ & PRO-G p. 961 \\
\hline 5 & Mesón & Alonso de Matute & Plaza de Bibarrambla & PRO-G p. 1095 \\
\hline 6 & Mesón & $\begin{array}{l}\text { De los herederos de la } \\
\text { condesa de Tamina }\end{array}$ & $\begin{array}{l}\text { Colación de Santa } \\
\text { Escolástica }\end{array}$ & PRO-G p. 1123 \\
\hline 7 & Mesón & Pedro de Carmona & Colación de Santiago & PRO-G p. 1342 \\
\hline 8 & Mesón & Andrés de Torres & $\begin{array}{l}\text { Colación de San Gil, } \\
\text { calle que sube del } \\
\text { hatabín a la calderería }\end{array}$ & $\begin{array}{l}\text { A.H.P.Gr., Escribanía de Francisco } \\
\text { Muñoz, prot. 14 (Granada), fol. } \\
\text { 392r-392v }\end{array}$ \\
\hline
\end{tabular}




\begin{tabular}{|c|c|c|c|c|}
\hline $\mathrm{N}^{0}$ & Mesón & Propiedad & Ubicación & Referencia \\
\hline 9 & $\begin{array}{l}\text { Mesón del } \\
\text { Moral }\end{array}$ & & $\begin{array}{l}\text { Colación de San Gil, } \\
\text { placeta de los } \\
\text { Almizqueros }\end{array}$ & $\begin{array}{l}\text { A.H.P.Gr., Escribanía de Francisco } \\
\text { Muñoz, prot. } 14 \text { (Granada), fol. } \\
\text { 556r-556v }\end{array}$ \\
\hline 10 & Mesón & $\begin{array}{l}\text { Monasterio de la } \\
\text { Trinidad }\end{array}$ & $\begin{array}{l}\text { Colación de Sta. } \\
\text { M. }{ }^{a} \text { Magdalena, calle } \\
\text { de los Mesones }\end{array}$ & $\begin{array}{l}\text { A.H.P.Gr., Escribanía de Fernando } \\
\text { y Gonzalo de Soria, prot. } 16 \\
\text { (Granada), fol. 769v-770v } \\
\text { A.H.P.Gr., Escribanía de Fernando } \\
\text { y Gonzalo de Soria, prot. } 16 \\
\text { (Granada), fol. 808r-809v } \\
\text { A.H.P.Gr., Escribanía de Fernando } \\
\text { y Gonzalo de Soria, prot. 16 } \\
\text { (Granada), fol. 1130r-1130v }\end{array}$ \\
\hline 11 & Mesón & Hernando Xauron & $\begin{array}{l}\text { Debajo de } \\
\text { Bibarrambla }\end{array}$ & $\begin{array}{l}\text { A.H.P.Gr., Escribanía de Gonzalo } \\
\text { Quijada, prot. } 19 \text { (Granada), fol. } \\
351 \mathrm{v}-352 \mathrm{v}\end{array}$ \\
\hline 12 & $\begin{array}{l}\text { Mesón de los } \\
\text { Correos }\end{array}$ & Hernando de Vaena & $\begin{array}{l}\text { Colación de la } \\
\text { Magdalena, debajo } \\
\text { de Bibarrambla }\end{array}$ & $\begin{array}{l}\text { A.H.P.Gr., Escribanía de Gonzalo } \\
\text { Quijada, prot. } 19 \text { (Granada), fol. } \\
\text { 351v - 352v } \\
\text { A.H.P.Gr., Escribanía de García } \\
\text { Castilla, prot. } 29 \text { (Granada), } \\
\text { fol. 354v - 355r }\end{array}$ \\
\hline 13 & Mesón & $\begin{array}{l}\text { Alonso de Córdoba } \\
\text { el Lobo }\end{array}$ & $\begin{array}{l}\text { Colación de la } \\
\text { Magdalena, } \\
\text { calle Real-calle de } \\
\text { los Mesones }\end{array}$ & $\begin{array}{l}\text { A.H.P.Gr., Escribanía de García } \\
\text { de Castilla, prot. } 21 \text { (Granada), } \\
\text { fol. 875v - 876r } \\
\text { A.H.P.Gr., Escribanía de Gonzalo } \\
\text { Quijada, prot. } 23 \text { (Granada), } \\
\text { fol.384r - 384v } \\
\text { A.H.P.Gr., Escribanía de Gonzalo } \\
\text { Quijada, prot. 31 (Granada), } \\
\text { fol. 121r - 123v }\end{array}$ \\
\hline 14 & Mesón & Bartolomé González & $\begin{array}{l}\text { Colación de Sta. } \\
\text { M. la Mayor, enfrente } \\
\text { del adarve de la puerta } \\
\text { de Bibalmazán }\end{array}$ & $\begin{array}{l}\text { A.H.P.Gr., Escribanía de Gonzalo } \\
\text { Quijada, prot. } 22 \text { (Granada), fol. } \\
\text { 202v - 203v } \\
\text { A.H.P.Gr., Escribanía de Gonzalo } \\
\text { Quijada, prot. } 23 \text { (Granada), } \\
\text { fol.355r- 355v } \\
\text { A.H.P.Gr., Escribanía de Gonzalo } \\
\text { Quijada, prot. } 26 \text { (Granada), fol. } \\
\text { 503r - 503v }\end{array}$ \\
\hline
\end{tabular}


DEL FUNDUQ A LA ALHÓNDIGA: UN ESPACIO ENTRE EL EMIRATO NAZARÍ Y EL REINO DE GRANADA...349

\begin{tabular}{|c|c|c|c|c|}
\hline $\mathbf{N}^{0}$ & Mesón & Propiedad & Ubicación & Referencia \\
\hline 15 & \begin{tabular}{|l} 
Mesón del \\
Toro
\end{tabular} & Juan de Lasarte & $\begin{array}{l}\text { Colación de la Magda- } \\
\text { lena, calle de los me- } \\
\text { sones }\end{array}$ & $\begin{array}{l}\text { A.H.P.Gr., Escribanía de Gonzalo } \\
\text { Quijada, prot. } 22 \text { (Granada), } \\
\text { fol. 231v - 232r } \\
\text { A.H.P.Gr., Escribanía de Gonzalo } \\
\text { Quijada, prot. } 23 \text { (Granada), } \\
\text { fol.384r - 384v } \\
\text { A.H.P.Gr., Escribanía de Gonzalo } \\
\text { Quijada, prot. } 23 \text { (Granada), } \\
\text { fol.410r - 410v } \\
\text { A.H.P.Gr., Escribanía de Gonzalo } \\
\text { Quijada, prot. } 31 \text { (Granada), } \\
\text { fol. } 121 \mathrm{r} \text { - 123v }\end{array}$ \\
\hline 16 & $\begin{array}{l}\text { Mesón del } \\
\text { Rastro }\end{array}$ & Diego Sánchez Dávila & $\begin{array}{l}\text { Fuera de la puerta de } \\
\text { Bibarrambla, lindando } \\
\text { con el río Darro }\end{array}$ & $\begin{array}{l}\text { A.H.P.Gr., Escribanía de Gonzalo } \\
\text { Quijada, prot. } 26 \text { (Granada), } \\
\text { fol. 236v - 240r }\end{array}$ \\
\hline 17 & Mesón & Diego Pavón & $\begin{array}{l}\text { Colación de la } \\
\text { Magdalena }\end{array}$ & $\begin{array}{l}\text { A.H.P.Gr., Escribanía de Diego } \\
\text { Gutiérrez, prot. } 30 \text { (Granada), } \\
\text { fol. } 81 \mathrm{r}-82 \mathrm{v}\end{array}$ \\
\hline 18 & Mesón nuevo & $\begin{array}{l}\text { Jurado Pedro } \\
\text { Hernández }\end{array}$ & $\begin{array}{l}\text { Extramuros puerta de } \\
\text { Elvira }\end{array}$ & $\begin{array}{l}\text { A.H.P.Gr., Escribanía de Diego } \\
\text { Gutiérrez, prot. } 30 \text { (Granada), } \\
\text { fol. 528r - 529r } \\
\text { A.H.P.Gr., Escribanía de Diego } \\
\text { Gutiérrez, prot. } 30 \text { (Granada), } \\
\text { fol. 828r -828v }\end{array}$ \\
\hline
\end{tabular}

\section{Bibliografía}

Alcocer Martínez, Adela, Catálogo documental del Archivo Municipal de Almería, Almería, Ayuntamiento de Almería, 1986.

Amara, Allaoua, "L'apport des sources textuelles à la connaissance de l'artisanat au Maghreb médiéval", en Sylvain Burri y Mohamed Ouerfelli (dir.), Artisanat et métiers en Méditerranée médiévale et moderne, Provence,Presses de l'Université de Provence, 2018,Confluent des sciences, pp. 205-218.

Arroyo Pérez, Encarnación et al., "Excavación arqueológica de urgencia en la alhóndiga Zayda en Puerta Real-Calle Mesones", Anuario Arqueológico de Andalucia/1992, T. III, 1995, pp. 279-283.

Asenjo Sedano, Carlos, Repoblación, mercedes y reparto de propiedades. En el Guadix reconquistado por los Reyes Católicos, Guadix, Diócesis de GuadixBaza, 2010.

Azuar Ruiz, Rafael, "El ribat en al-Andalus: espacio y función”, 'Ilu. Revista de Ciencias de las Religiones. Anejos, 10 (2004), pp. 23-38. 
Brunschvig, Robert, La berbérie orientale sous les Hafsides. Des origines a la fin $d u X V^{e}$ siècle, París, Adrien Maisonneuve, 1940, Publications de l'Institut d'Etudes Orientales d'Alger 8, 11.

Buendía Moreno, Antonio F. y Álvarez, José Javier, “Un posible Funduq nazarí intervención arqueológica puntual en el teatro cine imperial de Loja (2006)", Anuario Arqueológico de Andalucía/2006. Granada, 2010, pp. 1344-1348.

Cara Barrionuevo, Lorenzo, García López, José Luis y Morales Sánchez, Rosa, "Arqueología urbana e historia de la ciudad. El caso de Almería medieval", en Cara Barrionuevo, Lorenzo (ed.), Ciudad y territorio en al-Andalus, Granada, Athos-Pérgamos, 2000, Serie de Arqueología Medieval 2, pp. 167-192.

Cara Barrionuevo, Lorenzo y Morales Sánchez, Rosa, "Instalaciones industriales en la Almería medieval", Anuario Arqueológico de Andalucía/2003, T. III, 1, Sevilla, 2006, pp. 36-46.

Carballeira Debasa, Ana María, Legados píos y fundaciones familiares en al-Ándalus (Siglos IV/X - VI/XII), Madrid, Consejo Superior de Investigaciones Científicas, 2002, Estudios árabes e islámicos: Monografías 2.

Casal, María Teresa et al., "Informe-Memoria de la I.A.U. en el S.G.SS-1 (Parque de Miraflores y centro de congresos de Córdoba). Segunda Fase", Anuario Arqueológico de Andalucía/2003, T. III, 1, pp. 343-356.

Chalmeta, Pedro, El zoco medieval. Contribución al estudio de la historia del mercado, Almería, Fundación Ibn Tufayl de Estudios Árabes, 2010, Estudios andalusíes 3.

Clapés Salmoral, Rafael, "La actividad comercial de Córdoba en época califal a través de un edificio hallado en el arrabal de poniente", Anales de Arqueología Cordobesa, 25-26 (2014-2015), pp. 225-254.

Constable, Olivia Remie, Housing the Stranger in the Mediterranean World, Cambridge, Cambridge University Press, 2003.

Cressier, Patrice, "De un ribat a otro. Una hipótesis sobre los ribat-s del Magrib al-Aqsa (siglo IX-inicios del siglo XI)", en Azuar Ruiz, Rafael (ed.), El ribat califal. Excavaciones e investigaciones (1984-1992), Madrid, Casa de Velázquez, 2004, Collection de la casa de Velázquez 85, pp. 203-221.

Doumerc, Bernard, Venise et l'émirat hafside de Tunis (1231-1535), París, L'Harmattan 1999, Histoire et perspectives méditerranéennes.

Embí Najar, Gema y Mellado Sáez, Carmen, “Intervención arqueológica preventiva efectuada en el solar situado en calle Real numero 84 Antigua bodega el patio en el conjunto histórico de Almería", Anuario Arqueológico de Andalucia/2008, T. Almería, pp. 85-96.

Epalza, Mikel de, "Espacios y sus funciones en la ciudad árabe", Simposio Internacional sobre la ciudad islámica: ponencias y comunicaciones, Zaragoza, Institución Fernando el Católico, 1988, pp. 9-23. 
Fábregas García, Adela, “Acercamientos y acuerdos comerciales entre Granada y Venecia al filo de 1400", Anuario de Estudios Medievales, 40, 2 (2010), pp. 643-664.

Fábregas García, Adela, "Estrategias de los mercaderes toscanos y genoveses en el reino de Granada a través de la correspondencia Datini", Serta antiqua et mediaevalia, 5 (2001), pp. 259-304.

Fábregas García, Adela, "La vida económica del sultanato nazarí en su vertiente comercial”, en Malpica Cuello, Antonio, Peinado Santaella, Rafael G., Fábregas García, Adela (eds.), Historia de Andalucía. VIII coloquio, Granada, Universidad de Granada, 2009, pp. 81-101.

Feria García, Manuel C. y Arias Torres, Juan Pablo, "Un nuevo enfoque en la investigación de la documentación árabe granadina romanceada (ilustrado con dos traducciones inéditas de Bernardino Xarafí, escribano y romanceador del reino de Granada)", Al-Qantara, 26, 1 (2005), pp. 191-247.

Florido Esteban, Daniel David, "Intervención arqueológica en el yacimiento del Llano de Torroba, Rincón de la Victoria, Málaga", Anuario Arqueológico de Andalucía/2006. Málaga, 2010, pp. 3305-3309.

García López, José Luis, Cara Barrionuevo, Lorenzo, Flores Escobosa, Isabel y Morales Sánchez, Rosa, "La organización de espacios públicos y ámbitos privados en la Almería de los XI y XII. Excavaciones en la calle Mariana.”, Anuario Arqueológico de Andalucía/1992, T.III, 1995, pp. 13-29.

García Sanjuán, Alejandro, Hasta que Dios herede la tierra: los bienes habices en al-Andalus (siglos $X$-XV), Huelva, Universidad de Huelva, 2002, Arias Montano 57.

Gaspar Remiro, Mariano, "Partida de Boabdil allende con su familia y principales servidores", Revista del Centro de Estudios Históricos de Granada y su Reino, 2 (1912), pp. 57-111.

Gisbert, Josep Antoni, “Daniya, reflejo del Mediterráneo. Una mirada a su urbanismo y arqueología desde el mar (siglo XI)", en Suárez Márquez, Ángela (dir.), Almería, "puerta del Mediterráneo (ss. X-XI), Almería, Junta de Andalucía, Consejería de Cultura, 2007, Monografías del Conjunto Monumental de la Alcazaba 1, pp. 203-230.

Gómez Moreno, Manuel, Guía de Granada, Ed. facs., 2a ed., Granada, Universidad de Granada, 1998, Archivum 50.

González Jiménez, Manuel y Molina Molina, Ángel Luis, Los Milagros romanzados de Santo Domingo de Silos de Pero Marín, Murcia, Academia Alfonso X el Sabio, 2008.

González Sopeña, Inmaculada, "Arabismos y fiscalidad en el Reino de Granada", Dicenda. Cuadernos de Filología Hispánica 35 (2017), 109-130

Gordo Peláez, Luis J., "Pósitos, alhóndigas y alholíes: edificios municipales de abastecimiento en Castilla durante el siglo XVI", en Aranda Bernal, Ana María, Arquitectura vernácula en el mundo ibérico: actas del congreso in- 
ternacional sobre arquitectura vernácula, Sevilla, Universidad Pablo de Olavide, 2007, pp. 102-114.

Guerrero Lafuente, María Dolores, La memoria de la ciudad: el segundo libro de actas del cabildo de Granada (1512-1516), Granada, Universidad de Granada, 2007, Monumenta regni granatensis historica, acta 5.

Hernández Benito, Pedro, La Vega de Granada a fines de la Edad Media según las rentas de los habices, Granada, Diputación Provincial, 1990.

Hernández-Múzquiz, Rowena, "Pan y obras: la alhóndiga de Sevilla y las obras de 1402-1403”, Historia. Instituciones. Documentos, 35 (2017), pp. 355-403.

Íñiguez Sánchez, María del Carmen, “De la Málaga emiral a la nazarí. IAP. En las calles S. Souviron, Olozaga y Marqués (Málaga)", Anuario Arqueológico de Andalucía/2006. Málaga, 2010, pp. 3398-3425.

Jiménez Castillo, Pedro y Navarro Palazón, Julio, "Casas y tiendas en la Murcia andalusí. Excavación en el solar municipal de Plaza de Belluga”, Memorias de arqueología, 10 (1995), pp. 490-532.

Jiménez Castillo, Pedro y Navarro Palazón, Julio, "Murcia omeya”, en El esplendor de los omeyas cordobeses. La civilización musulmana de Europa occidental, Granada, Fundación El Legado Andalusí, 2001, pp. 132-151.

Jiménez Puertas, Miguel, "La evolución del sistema monetario nazarí", Gaceta numismática, 150 (septiembre, 2003), pp. 31-49.

Ladero Quesada, Miguel Ángel, "Mercedes reales en Granada anteriores al año 1500. Catalogo y comentario", Hispania, 112 (1969), pp. 355-424.

Lagardère, Vincent, Histoire et société en occident musulman au moyen âge. Analyse du Mi yār d'al-Wanšarīsī, Madrid, Casa de Velázquez, 1995, Collection de la Casa de Velázquez.

López Pérez, María Dolores, "Política y comercio en el Mediterráneo occidental medieval: la conformación del cuadro diplomático y su repercusión en los intercambios económicos Magreb-Corona de Aragón (ss. XIII-XV)", en Cavaciocchi, Simonetta (ed.), Relazioni economiche tra Europa e Mondo islámico secc. XIII-XVIII, Grassina, Le Monnier, 2007, pp. 419-449.

Martí Oltra, Javier y Burriel Alberich, Josep, “Comerciar en tierra extraña. La alhóndiga musulmana de la calle Corretgeria de Valencia”, en Historia de la ciudad. V: Tradición y progreso, Valencia, Colegio Oficial de Arquitectos de la Comunidad Valenciana, 2008, pp. 41-60.

Martínez Salvador, Carmen, "Sobre la entidad de la rábita andalusí omeya. Una cuestión de terminología: ribat, rábita y zawiya", en Azuar Ruiz, Rafael (ed.), El ribat califal. Excavaciones e investigaciones (1984-1992), Madrid, Casa de Velázquez, 2004, Collection de la casa de Velázquez 85, pp. 173-201.

Miralles Lozano, María Eulalia, "Repartimiento de Baza”, Tesis Doctoral, Universidad de Murcia, 1988. 
Molina Expósito, Antonio, “Actividad arqueológica preventiva en la Avenida de América, no 5 (Antiguo Hotel Gran Capitán), de Córdoba”, Anuario Arqueológico de Andalucía/2008, T. Córdoba, pp. 1624-1635.

Moreno Trujillo, María Amparo, La memoria de la ciudad: el primer libro de actas del Cabildo de Granada (1497-1502), Granada, Universidad de Granada, 2005, Monumenta Regni Granatensis historica. Diplomata.

Moreno Trujillo, María Amparo, Obra Sierra, Juan María de la y Osorio Pérez, María José, Los libros de rentas municipales de la ciudad de Granada en el siglo XVI, Granada, Universidad de Granada, 2015, Monumenta Regni Granatensis historica. Diplomata.

Navarro Palazón, Julio y Jiménez Castillo, Pedro, "Algunas reflexiones sobre el urbanismo islámico”, Artigrama, 22 (2007), pp. 259-298.

Navarro Palazón, Julio y Jiménez Castillo, Pedro, Las ciudades de Alandalús, Zaragoza, Instituto de Estudios Islámicos y del Oriente Próximo, 2007, Conocer Alandalús 5.

Obra Sierra, Juan María de la, Catálogo de protocolos notariales: Granada 15051515, Tesis Doctoral (inédita), Granada, 1986, [en línea], disponible en: http://digibug.ugr.es/handle/10481/6387, [consultado el 11/09/2019].

Ortega Cera, Ágatha, "Rentas mayores y menores de la ciudad de Granada (14951504)", Chronica Nova, 31 (2005), pp. 237-303.

Perdiguero Ayala, Carolina y Pareja Pareja, Francisco Ángel, "La reglamentación de la alhóndiga de Vélez Málaga: Las ordenanzas reales de 1513”, Actas del III Congreso de Historia de Andalucía, Sevilla, Juntade Andalucía, Consejería de Cultura y Medio Ambiente, 2001, pp. 281-291.

Pereira Iglesias, José Luis, "La alhóndiga cacereña en el siglo XVI", Norba. Revista de arte, geografia e historia, 2 (1981), pp. 205-220.

Petti Balbi, Giovanna, Negoziare fuori patria. Nazioni e genovesi in età medievale, Bologna, CLUEB, 2005, Itinerari medievali 10.

Rodríguez Aguilera, Ángel, La puerta de Bibarrambla de Granada y el flanco occidental de la muralla de la madina hasta Bibalmazán, Granada, Patronato de la Alhambra y Generalife, 2018.

Ruiz Parra, Inmaculada, "Excavaciones arqueológicas en el solar de la c/ Conde Valle de San Juan, esquina c/ Pascual de Murcia”, Memorias de Arqueología, 5 (1990), pp. 416-426.

Seco de Lucena Paredes, Luis, "Escrituras árabes de la Universidad de Granada", Al-Ándalus, 35, 2 (1970), pp. 315-354.

Seco de Lucena Paredes, Luis, "Las puertas de la cerca de Granada en el siglo XIV”, Al-Ándalus, 6 (1942), pp. 438-458.

Sennoune, Oueded, "Fondouks, khans et wakalas à Alexandrie à travers lesrécits de voyageurs", Annales islamologiques, 38 (2004), pp. 453-489.

Torres Balbás, Leopoldo, "Las alhóndigas hispanomusulmanas y el Corral del carbón”, Al-Ándalus, 11 (1946), pp. 447-484. 
Torres Balbás, Leopoldo, Ciudades hispanomusulmanas, Madrid, Instituto Hispano-Árabe de Cultura, 1971.

Torres Balbás, Leopoldo, "Rábitas hispanomusulmanas", Al-Andalus, 13, 2 (1948), pp. 475-491.

Trillo San José, Carmen, "Modificaciones castellanas en la ciudad de Granada al final de la Edad Media. El control del comercio", Revista del Centro de Estudios Históricos de Granada y su Reino, 7 (1993), pp. 27-40.

Tristán García, Francisco, “De Basta a Baza. Notas de urbanismo en el tránsito de la ciudad islámica a la cristiana 1480-1530", Péndulo. Papeles de la Bastetania, 2 (2001), pp. 38-69.

Valérian, Dominique, "Le Fondouk, instrument du controle sultanien sur les marchands étrangers dans les ports musulmans (XII-XV Siècles)?, en Claudia Moatti (dir.), La mobilité des personnes en méditerranée de l'antiquité à l'époque moderne, Roma,École française de Rome, 2004, Collection de l'École française de Rome 341, pp. 677-698.

Vázquez Navajas, Belén, "El agua en la Córdoba andalusí. Los sistemas hidráulicos de un sector del Yanib al-Garbi durante el Califato Omeya", Arqueología y Territorio Medieval, 20 (2013), pp. 31-66.

Vázquez Navajas, Belén, "Arqueología hidráulica en los arrabales occidentales de la Córdoba omeya", Tesis Doctoral, Universidad de Córdoba, 2016, [en línea], disponible en: https:/helvia.uco.es/xmlui/handle/10396/13732, [consultado el 11/09/2019].

Villanueva Rico, María del Carmen, Habices de las mezquitas de la ciudad de Granada y sus alquerías, Madrid, Instituto Hispano-Árabe de Cultura, 1961

Zomeño Rodríguez, Amalia, "Del escritorio al tribunal. Estudio de los documentos notariales en la Granada nazarí", en Monferrer Sala, Juan Pedro y Marcos Aldón, Manuel (coords.), Grapheion. Codices, manuscritos e imágenes. Estudios filológicos e históricos, Córdoba, Universidad de Córdoba, 2003, pp. 75-98.

Zomeño Rodríguez, Amalia, "Los notarios musulmanes de Granada después de 1492”, Cuadernos del CEMYR, 22 (2014), pp. 195-209.

Recibido: $12 / 09 / 2019$

Aceptado: 05/12/2019 